Portland State University

PDXScholar

5-23-1975

\title{
A Descriptive Study of Five Child Day Treatment Centers
}

Virginia Spurkland

Portland State University

Joyce Edwards

Portland State University

Follow this and additional works at: https://pdxscholar.library.pdx.edu/open_access_etds

Part of the Social Work Commons

Let us know how access to this document benefits you.

\section{Recommended Citation}

Spurkland, Virginia and Edwards, Joyce, "A Descriptive Study of Five Child Day Treatment Centers" (1975). Dissertations and Theses. Paper 2250.

https://doi.org/10.15760/etd.2247

This Thesis is brought to you for free and open access. It has been accepted for inclusion in Dissertations and Theses by an authorized administrator of PDXScholar. Please contact us if we can make this document more accessible: pdxscholar@pdx.edu. 
AN ABSTRACT OF THE GROUP THESIS OF Virginia Spurkland and Joyce Edwards

for the Master of Social Work presented May 23, 1975.

Title: A Descriptive Study of Five Child Day Treatment Centers

APPROVED BY MEMBERS OF THE GROUP THESIS COMMITTEE:

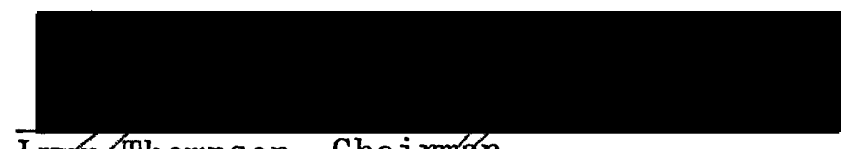

Lypy-Thompson, Chairman

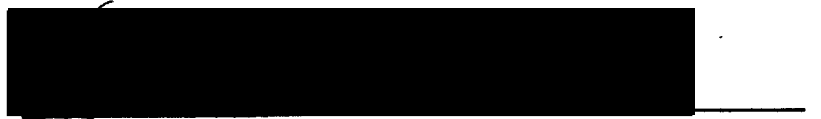

June Dunn
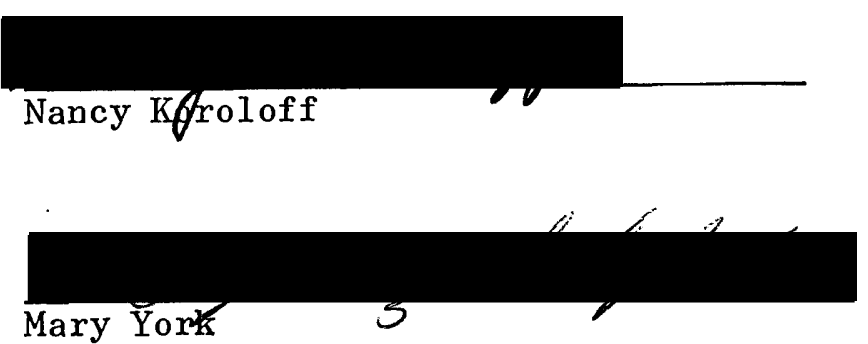

This thesis is a descriptive study of five child day treatment centers in 0regon. Its purpose was to generate hypotheses about the relationships between parent reactions to the day treatment center, the center's theoretical orientation toward treatment, and the organizational structure of the center.

The five centers involved in the study were: Poyama Land in Independence, Oregon; the Child Psychiatric Day Treatment Center in Portland, Oregon; Mid-Columbia Children's Center in The Dalles, Oregon; the Child Center in Eugene, Oregon; and Edgefield Lodge in Troutdale, Oregon. These centers were selected for this study because of their proximity to the Portland area and their requirement that parents be 
involved in their child's treatment program.

Data were collected by a parent questionnaire, a staff questionnaire, and an interview with the executive director of each program. All three data collection instruments were designed specifically for use in this study.

Each of the (135) parents who had a child in one of the centers for at least one month and for whom the center had some expectations for involvement were sent questionnaires. All staff (51) in each of the five centers who were employed at least half-time were asked to complete questionnaires.

Data analysis varied with the instrument and the type of data collected. Questions on the staff questionnaire pertaining to staff role in decision making were factor analyzed as were the questions on the parent questionnaire pertaining to parent attitudes toward the day treatment center. Factor analysis simplified the interpretation of the data by reducing the number of variables on the staff questionnaire from nine to three, and on the parent questionnaire from twentyfour to five. Factor scores were computed for each respondent and factor score means were calculated by center for both parents and staff. Nominal data on the staff questionnaire were dealt with by the construction of contingency tables and inspection of differences between observed and expected frequencies for each cell. Data from the interview guide were descriptive and were synthesized and reported in narrative form.

It was found that parents of each center tended to respond favorably to the day treatment center with which they are associated. There 
wete trends in parent responses which, when evaluated in the context of descriptive data on each center, generated four hypotheses for furthur research. These hypotheses are:

(1) this greater the consensus between director and staff on theoretical orientation toward treatment of a child and his family, the more favorable parent reaction to the day treatment program.

(2) the more specific and clearly articulated the requirements for parent involvement, the more favorable parent reaction to the day treatment program.

(3) the greater the number of parent-staff contacts, the more favorable parent reaction to the day treatment program.

(4) the greater the use of parent groups, the more favorable parent reaction to the day treatment program. 


\title{
A DESCRIPTIVE STUDY OF FIVE CHILD \\ DAY TRFATMENT CENTERS
}

by

\author{
VIRGINIA SPURKLLAND
}

JOYCE EDWARDS A group thesis submitted in partial fulfillment of the
requirements for the degree of

MASTER OF SOCIAL WORK

Portland State University

1975 
TO THE OFFICE OF GRADUATE STUDIES:

The members of the Committee approve the thesis of Virginia

Spurkland and Joyce Edwards presented $\frac{\text { May 12, } 1975}{\text { (Date) }}$
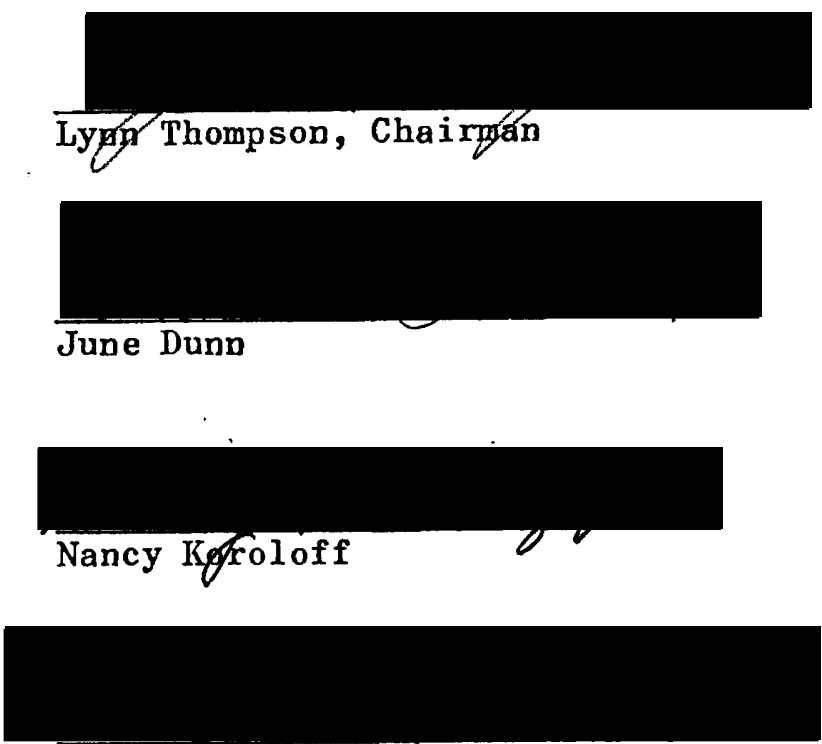

Mary York

APPROVED :

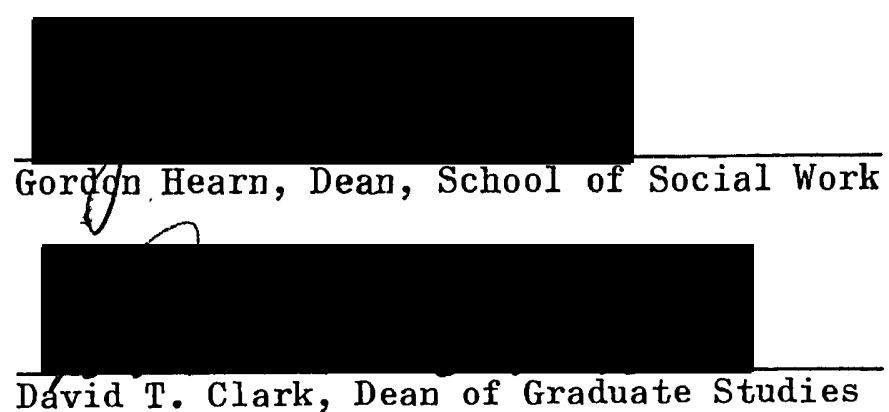

June, 1975 


\section{ACKNOWLEDGEMENTS}

We would like to express our deep appreciation and indebtedness to those whose efforts and contributions made this study possible.

The Advisor to the Project

Lyon Thompson, Portland State University School of Social Work

The Thesis Committee

June Dann, Portland State University School of Social Work; Naney Koroloff, Portland State University School of Social Work; Dr. Mary York, Portland State University Education Department

The parents, staff members, and directors of the participating child day treatment centers 
ACKNOWLEDGEMENTS . . . . . . . . . . iii

LIST OF TABLES . . . . . . . . . • • v

CHAPTER

I INTRODUCTION ......... . . 1

II REVIEW OF THE LITERATURE . . . . $\therefore$. 4

III METHODOLOGY . . . . . . . . . 9

Introduction . . . . . . . . 9

The Population ... . . . . . 9

Construction of Instruments . . . . 12

Administration of Research
Instruments . . . . $\quad 15$

Data Analysis . . . . . . . 18

IV FINDINGS . . . . . . . . . . 21

Introduction . . . . . . . . 21

The Interview Guide . . . . . . . 21

The Staff questionnaire . . . . . 28

The Parent Questionnaire... . . 41

V DISCUSSION AND CONCLUSIONS . . . . $\quad 51$

BIBLIOGRAPHY . . . . . . . . . . 56

APPENDIX . . . . . . . . . . . 59 


\section{LIST OF TABLES}

TABLE

PAGE

I Staff Reason for Involving Parents in Child

Treatment . . . . . . . 30

II Staff 0pinion About Parent Role in Intake . • 32

III Staff Opinion About Parent Role in the

Hiring of New Staff . . . . . 33

IV Staff Opinion About the Role of the Parents in

Evaluation of the Child's Progress ... . 35

V Staff Opinion About Parent Access to their

Childs File . . . . . . . 36

VI Mean Staff Scores on Factor 1: Integration

into 0verall Functioning of Center $\quad \therefore \quad 38$

VII Mean Staff Scores on Factor 2: Upward

Communication . . . . . .

VIII. Mean Staff Scores on Factor 3: Alienation from

Job Requirements . • . . . . . 39

IX Channels of Communication in the Day Treatment Centers ......... 40

X Percentage Return of Parent Questionnaires by.

Center ................ 41

XI Number of Reported Times Parents Talked with a

Staff Member the Month Prior to Completion

of the Questionnaire . . . . . . . 42 
TABLE

XII Number of Parent Group Meetings Attended by Parents the Month Prior to Completion of the Questionnaires . . . . . . . 42

XIII Number of Parent Visits to Child's Classroom the Month Prior to Questionnaire Completion. . 43

XIV Number of Brief and Casual Conversations with a

Staff Member the Month Prior to

Questionnaire Completion . . . . . • •

XV Number of Times Picked Up or Took Their Child to

the Center the Month Prior to Questionnaire Completion ....... 44

XVI Number of Times Parents Kept an Appointment with

a Staff Member the Month Prior to

Questionnaire Completion ........ 44

XVII Number of Other Reported Contacts Parents Had with the Centers the Month Prior to Questionnaire Completion . . . . . . . . 45

XVIII Factor Score Means: Factor I - Mutuality of Relationship Between Parents and Staff. . . 46

XIX Factor Score Means: Factor 2 - Parent Laterality orientation ........... 47

XX Factor Score Means: Factor 3 -Communication with Parents about the Child's Treatment Program . . . . . . . . . . . 
TABLE

XXI Factor Score Means: Factor 4 - Parent Satisfaction with the Requirements for Involvement in the Program .................48

XXII Factor Score Means: Factor 5 - Parent General

Satisfaction with the Day Treatment Program . 49

XXIII. Factor Analysis on Parents: Orthogonal Factor Matrix .............. 74

XXIV Parent Questionnaire: Distribution of Questions

Over the Fite Factors . . . . . . . 75

XXV Factor Analysis on Staff: Orthogonal Factor Matrix ............ 76

XXVI Staff Questionnaire Distribution of Questions

Over the Three Factors . . . . . . 77

XXVII Job Classifications of Staff Members by Center . 78

XXVIII Educational Level of Staff Members by Center . . 79

XXIX Field of Educational Concentration of Staff

Members by Center .......... 80

XXX Percentage Return of Questionnaires by Parent

Category in Population . . . . . . 81

XXXI Distribution of Parent Categories in the Day.

Treatment Centers .........

XXXII Mean Number of Months the Children of Parents

in the Population Have Participated in the

Day Treatment Programs ........ 
viii

TABLE

XXXIII Last year of School Completed by Parents in the

Population . . . . . . . . . 82

XXXIV Age Group of Parents in the Population ....

83 


\section{CHAPTER I}

\section{INTRODUCTION}

Parent involvement in a child's treatment is frequently a requirement of day treatment centers for emotionally disturbed children. The underlying premise of this requirement is the belief that parent involvement facilitates the child's treatment and promotes more rapid and lasting improvement: Day treatment staff are of ten faced with the task of involving parents who are unresponsive. Lack of parent involvement then becomes an area of concern for day treatment programs.

A review of the literature reveals that very little has been written on day treatment programs and/or the involvement of parents in day treatment programs. There are articles that describe the approaches taken by individual programs to treatment of children and their families, but there has been no attempt to systematically uncover the variables related to the involvement of parents in child day treatment programs. While there are many researchable questions in this area, not all of them share the same degree of potential utility in the planning and delivery of services to children and their families. For example, a study might attempt an exploration of the parent personality traits associated with the successful involvement of parents in the day treatment programs. Such a study might prove interesting but it would have limited utility for use by the day treatment programs in improving the involvement of parents as the alteration of personality characteristics of uninvolved parents is 
an unrealiatic expectation. Another area of possible research around the question of parent involvement in child day treatment might focus on an examination of the day treatment programs themselves and the parent reactions to the programs. This approach seems more useful if the goal is to improve the level of involvement of the parents in the day treatment programs. Changes that can be made in the programs themselves are more accessible than effecting change in individual parent characteristics. This rationale directed the focus of this thesis which was designed to generate hypotheses about the relationships between elements of the day treatment programs and the parent reactions to the programs.

This thesis is a descriptive study focusing on the reactions of parents to five child day treatment centers in 0regon. Parent reactions include the types and number of contacts the parents have with the centers and their attitudes toward the centers:- Parent reactions are evaluated in the context of descriptive data which focus on the center's theoretical orientation toward treatment and the organizational structure of each center. Theoretical orientation toward treatment means the basis by which staff determine the types of interventions used in treatment of children and parents. Organizational structure, in this study, refers to the decision making patterns within the center and the role relationships between administration, staff, and parents.

Theoretical orientation toward treatment, organizational structure, and client reactions to services are variables dealt with in 
studies in the fields of social casework and clinical psychology. However; these studies have not been conducted in child day treatment programs nor has there been an attempt to evaluate client reactions in the context of organizational structure and theoretical orientation toward treatment. This thesis represents a departure from previous research by focusing on child day treatment programs and combining the variables of client reaction, organizational structure, and theoretical orientation toward treatment. 
CHAPTER III

\section{METHODOLOGY}

\section{INTRODUCTION}

This study was designed to provide descriptive data focusing on parent reactions to child day treatment programs in the context of descriptions of the programs along the dimensions of theoretical orientation toward child treatment and organizational structure of the center. Data were collected by means of a parent questionnaire, a staff questionnaire, and an interview with the executive director of each program.

\section{THE POPULATION}

Selection of the respondents involved three discrete decisions: one for the agency sample, one for the staff respondents, and one for the parent respondents. The population of program directors was determined by the agency sample. Each of these selection processes will be described below.

\section{The Agency Sample}

Five child day treatment centers in 0regon were selected on the basis of two criteria. In order to be included in the sample it was necessary that the day treatment center have expectations for some type of parent involvement in the program. The other consideration in the selection of the agency sample was accessibility in terms of distance from the Portland area. This criterion was introduced due to cost limitations of the study and accompanying difficulties in administra- 
ment in the following areas: achievement; affiliation; and influence or power. Fristration of role-takers within organizations occurs when the above desires go unsatisfied. Clarification of goals within the organization reduces confusion about desired results and enables various personnel to realize how their roles interrelate. Thus, means for achievement are made clear. Needs for affiliation can be fulfilled through a unified spirit of mutual support and respect. Finally, gratification of striving for power is achieved through allowing for influence at all levels of the organization (Schmuck, Runkel and Langmeyer, 1969).

Lewis (1969) described two discrete organizational models in his article, "The Organizational Structure of the Therapeutic Team." The hierarchical model is characterized by fixed role definitions, restriction of decision making to staff in leadership positions, and simple level to level communication. Group decision making, flexible role definitions, and open communication between all staff members are characteristics of the equalitarian organizational model. Some researchers have suggested that the equalitarian team is the more effective problem solving structure while the hierarchical team offers the better decision implementing approach. Lewis (1969) suggests a compromise model involving open communication and shared decision making but with the addition of a permissive leader who takes final responsibility for decisions. According to Lewis, it is also essential for role definitions to be neither rigid nor blurred. He suggests that professional identity should be maintained but that role defusion is permitted in the interest of the patients. 
In other studies, decision making structure has been related to organizational size. Michels (Dunkerley, 1972) asserts, "As the size of a group increases, so does the extent of the leader's authority, his personal power, and the amount of delegation permitted in the decision making process."

Several studies have related the above feature of organizations to the attitudes of the people served by the organizations. It has been suggested (Schmuck and Schmuck, 1971) that in schools where power is more equally distributed between administration and staff, the quality of teacher-student relationships improve. Lewis (1969) states, "Team members' investment in therapeutic activity with patients is in direct proportion to their responsibility for making decisions about patient care." However, he goes on to say that "a team model with many equalitarian features tends to precipitate egocentric staff needs, and covert staff disagreement has a destructive impact on patients." Etzioni studied the relationship of patient involvement to the different types of sanctions used. He found that positive involvement is associated with persuasion, manipulation and suggestion. Neutral involvement is associated with remunerative sanctions and negative involvement with coercive power (Julian, 1968).

Early studies in theoretical orientation were predicated on the belief that one method of treatment would prove to be most effective in all cases. These studies focused on the form of treatment as it affected the individual client in psychotherapy. Interest in theoretical orientation as an organizational dynamic has developed only recently. One such study of patient attitudes towards staff roles and institu- 
tional treatment methods resulted in findings pertinent to the present study. The researchers found that patient attitudes toward treatment were largely determined by the setting in which the treatment was received. "The institution may, to a large extent, condition the patient's attitude to his illnesis. and the appropriate treatment for it" (Caine and Smail, 1968). Additionally; "the interactions between the orientation of those carrying out the treatment and the attitudes toward it of those receiving treatment may have important implications both for morale and prognosis" (Caine and Smail, 1968).

The concept of laterality as postulated by Rosengren and Lefton is relevant to the study of treatment orientation. Rosengren theorized that the "internal structure and dynamics of an organization are closely related to the manner by which organizations intervene in the life course of their clients" (Rosengren, 1970). Plus laterality as defined by Lefton (Rosengren, 1970) is the "extent to which client. serving organizations take the whole person into account." Minus laterality is a "purposively restricted focus on specific or segmented features of clients." From the client's point of view, a plus laterality attitude is indicated when the client believes the organization ought to understand his total life situation. A minus laterality viewpoint is indicated whenever the "client perceives the organization's legitimate interest in him as limited" (Rosengren, 1970). Some researchers have suggested that the concept of laterality can be useful in the organization and development of therapeutic interventions that are relevant to the client's individual needs and personality patterns (Wolkon, Lanier, and Moriwaki, 1971). 
Examination of the literature reveals that few studies have been done on client reaction to services. Most have been in the fields of casework and clinical psychology and have focused on the client's assessment of treatment outcome. Ore such study (Horenstein, Houston and Holmes, 1973) found "that contrary to the usual assumption clients may be good (or at least better than their therapists) at evaluating their therapy progress." Several other studies have found considerable discrepancy between client-worker assessment of treatment effectiveness. Researchers have questioned the meaning of this discrepancy and have stressed the need for further systematic studies of client reaction to services. 


\section{REVIEW OF THE LITERATURE}

The literature review focuses on: theoretical orientation of treatment programs; organizational structure, particularly role relationships and decision making process; and the client's viewpoint on services they receive.

Organizational research is replete with studies on decision making process and role relationships among staff and administrative personnel. Early research was concentrated on industrial organizations with more recent additions in the area of social service organizations and schools. Numerous studies have associated staff job satisfaction with their perception of the degree of influence they have on decision making (Schmuck and Schmuck, 1971). While some investigators have suggested a direct relationship between satisfaction and influence, others have demonstrated that several factors effect the degree of decision making power one desires: Such factors include age, sex, job level, role conflict, and the degree of interest in the decision making issues in question (Alutto and Belasco, 1972).

Role relationships among administration, staff, and those served by the organization is a function of the organization's structure, Theoreticians postulate that role taking assumes an interaction between role-takers. A breach in the system of role interactions is remedied through correcting patterns of interaction. The emphasis is on the dynamics of the interactional system rather than on the functioning of individual role-takers. It is also hypothesized that an individual's functioning in an organization is influenced by his emotional invest- 
tion of the research from greater distances. The five day treatment centers meeting these criteria and agreeing to participate in the study were: Edgefield Lodge in Troutdale, Oregon; The Child Center in Eugene, Oregon; The Mid-Columbia Children's Center in The Dalles, Oregon; Poyama Land in. Independence, Oregon; and the Child Psychiatric Day Treatment Center in Portland, Oregon

\section{The Parent Population}

The relatively small size of the total parent population in all five centers made it necessary to include all parents who met the following specifications: 1) The parent's child had to have been in the program at least one month and 2) the day treatment program had to have expectations for some type of involvement in the program by that parent. The first of these specifications was used to determine the parent population since the study focuses on parent reactions to the day treatment programs. It was felt that less than a month's exposure to the program was inadequate for the parent to have much basis for reaction to that program. The second specification for inclusion in the parent population also arises directly from the purpose of the study which focuses on the issue of parent involvement.

There were 135 parents in the population. Twenty of them were participants in the Child Center, eighteen were from the Mid-Columbia Children's Center, forty were from Edgefield Lodge, twenty-three were from Poyama Land, and thirty-one were from the Child Psychiatric Day Treatment Center, One center noted that some parents involved at the time of population selection would no longer be active participants by 
the time the questionnaires were administered. It was decided that these parents would be included in the population as they would still be in contact with the center through follow-up services. An additional coding category designating these parents was added and the other programs were notified of this decision and were asked to assign code numbers to these parents.

\section{The Staff Population}

Inclusion in the staff population was contingent upon at least half-time employment in the day treatment center. This definition excluded personnel such as consultants who spend only a few hours a week at the center. The rationale for this definition of staff population arises from the objectives of the study which focus on describing characteristics of the day treatment programs and parent reactions to those programs. It was felt that to be an integral part of the program required at least half-time employment. Staff employed half-time and more were considered to be those who would have the most contact with parents and who would most determine the character of the programs.

AIl staff members meeting this requirement were included in the population due to the small number of staff in all programs. The executive directors were considered to be in a separate category as they were the targets of a different data collection instrument than were the other staff members. There was a total of 51 staff in the population. There were eight staff from the Child Center, nine from Poyama Land, thirteen from Edgefield Lodge, fifteen from the Child Psychiatric Day Treatment Center, and six from the Mid-Columbia Children's Center. 


\section{CONSTRUCTION OF INSTRUMENTS}

\section{The Parent Questionnaire}

The parent questionnaire was designed to measure parent reactions to the day treatment programs. Parent reaction was, for the purposes of this study, broken into two components. One of these components deals with the numerical frequency of parent contacts with the day treatment center andits staff. The first part of the parent questionnaire asks parents to record the number and type of contacts they had. with the center the month prior to completion of the questionnaire.

There were twenty-four items on the parent questionnaire designed to measure parent attitudes toward various aspects of the center programs. Some of the questions were designed to measure parent laterality orientations to the program as defined by Rosengren (1970). 0ther questions were designed to measure parent feelings about staff commuication with them. 0thers were geared toward measurement of general feelings of satisfaction or dissatisfaction with the program. Some of the questions were to measure the parents.' feelings about their participation in decision making in the program, and some were to measure parent reactions to the center's requirements for parental involvement.

These questions were not pre-tested as they are specific to child day treatment programs and another group having the same characteristics as the sample was unavailable. The questionnaire was, however, factor analyzed on the twenty-four questions measuring parent attitudes toward the program. Factor analysis served two functions for this study. By condensing the twenty-four questions into five factors, data 
analysis was greatly simplified, as without it each of the twenty-four questions would have had to be considered separately. Pertinent to the discussion of questionnaire construction is the other function served by factor analysis. The method of factor analysis gives a lot of information on the construction of the questionnaire and, in the absence of pre-testing, can lend some sense of validity to the questionnaire. The factor analysis resulted in five independent factors which were subsequently named: 1) Mutuality of the Relationship Between Parents and Staff; 2). Parent Laterality Orientations; 3) Staff Communication with Parents about their Child's Treatment Program; 4) Parent Satisfaction with Requirements for Involvement in the Program; 5) General Satisfaction with the Day Treatment Program.

Only three of the questions did not load on any of the factors. The distribution of questions over the factors matched closely the intent of the questions when the questionnaire was designed. The concept of parent role in decision making did not emerge as a separate category as planned but became a part of the factor "Mutuality of Relationship Between Parents and Staff". (See Appendix for a breakdown of questions into their corresponding factors and the factor matrix). Three of the questions loaded fairly equally on two factors. All of these questions involved Factor 4 , Parent Satisfaction with Requirements for Involvement. Two of the three questions also loaded on Factor 2, Parent Laterality 0rientation, and one of them also loaded on Factor 1, Mutuality of Relationship Between Parent and. Staff. These are not illogical combinations, but indicate that some questions were related to more than one factor. 
There are three other questions on the parent questionnaire, not yet mentioned, that deal with control variables intended to establish comparability between the day treatment centers.

The parent questionnaire was an objective one to facilitate analysis. Considerable attention was given to the format of the questionnaire as a major concern was the percentage of return on the questionnaire. This was particularly critical as the population was relatively small. The questionnaire was designed to require approximately fifteen minutes to complete and was professionally printed on a foldout sheet that made the entire questionnaire visible at once. This design was to accentuate its brevity and increase the probability of return.

\section{The Staff Questionnaire}

The staff questionnaire was designed to provide information on three areas: the staff's theoretical orientation toward treatment as it relates to involving parents, staff ideas about parent roles in different phases of the center's operation, and staff feeling about their own roje in agency decision making. This questionnaire, like the parent questionnaire, was objective with most of the questions being in the form of multiple choice. There were spaces for.writing in alternative responses for some of the questions in order not to produce bias by forcing a choice not representative of a staff members thinking on the subject. The questions on the staff member's role in decision making were adapted from a questionnaire from James L. Price, Handbook of Organizational Measurements (1972). The questionnaire in Price's 
book dealt with large business organizations and changes were made in deleting those areas not applicable to a small social service agency and in changing the wordings of the questions to make them suitable to the day treatment center.

The nine questions on staff role in decision making were factor analyzed resulting in three factors which were named: 1) Integration into Overall Functioning of the Center; 2) Upward Conmunication; and 3) Alienation from Job Requirements. Distribution of questions across the factors was not very even with five questions loading on Factor 1, two questions on Factor 2, and one loading on Factor 3. 0ne question did not load on any of the factors. (See Appendix for the factors and corresponding questions and the factor matrix.)

The staff questionnaire also contained three questions on staff positions, educational level, and field of training. These questions were added, not to distinguish one staff member's responses from another's, but to provide an overall description of each center's staff.

\section{ADMINISTRATION OF RESEARCH INSTRUMENTS}

\section{The Parent Questionnaire}

Each parent who met the population criteria was assigned a code number by agency personnel according to printed coding instructions sent to each center. (See Appendix). Code numbers were used to insure the confidentiality and anonymity of the respondents. The code system incorporated some identifying characteristics of the respondents such as whether they were mothers or fathers; natural, foster, step or other parent figure; the length of time the child had been in the program; and 
the parent's racial group. It was later found that, due to the time delay between coding and questionnaire administration, the code for length of time the child had participated in the program became meaningless. This information was then incorporated into the parent questionnaire to increase the reliability of data on the length of time the child had participated in the program.

The coded questionnaires were then mailed by the centers directly to the parents along with letters from the center directors asking for cooperation in completing the questionnaires and an explanatory letter from the researchers. Stamped, addressed envel opes were enclosed that provided for the questionnaires to be returned directly to the researchers. One center, Poyama Land, deviated slightly from this method of administration. Instead of mailing the questionnaires to the parents, they gave them to the parents at group meetings. The questionnaires were mailed directly to us, however, so it seems unlikely that precautions taken to insure confidentiality were injured. The variation in procedure by Poyama Land probably does account for their somewhat higher return than the other centers and may have had some other effect on the results. This possibility will be discussed in Chapter IV.

After approximately four weeks. had lapsed, code numbers of questionnaires not yet received were reported to the centers and the centers were requested to re-contact those parents. It then became evident that this method of follow-up was inadequate as it did not take into account the fact that the original questionnaires might have been lost by the parents. A follow-up letter was prepared (See Appendix). and the centers mailed second questionnaires to all parents whose 
completed questionnaires had not yet been received. Two weeks were allowed for return of follow-up questionnaires.

\section{The Staff Questionnaire}

Arrangements were made with the executive directors to visit each center at the time of a staff meeting in order to administer the questionnaire to the staff as a group. Administration as a group was deemed to insure greater validity of the results. It was felt that administration by mailing the questionnaires to the staff or asking the director to distribute questionnaires to the staff would contribute to the problem of discussion among the staff with the result that responses would tend to reflect group opinion and not individual staff opinions. Each group of staff was read a brief paragraph which gave instructions for completion of the questionnaire, asked the staff to complete the questionnaires, and indicated that there would be an opportunity to ask questions about the study after all the staff had completed the questionnaires. This was done to decrease bias which might have occurred had discussions and questions been allowed before completion of the questionnaire.

There were a few instances where staff included in the population were not present at the staff meeting. Questionnaires were left at the center for these staff members along with stamped addressed envelopes for return of the questionnaires directly to the researchers.

\section{Interview with Executive Directors}

The time for the interview with the executive director was prearranged and generally occurred the hour preceding administration of 
the staff questionnaire. All interviews were held in the office of the executive director. Both researchers attended each interview and took one of two roles. In each interview, one researcher took the role of primary interviewer asking all the questions and taking the major role in probing to obtain necessary information. The other researcher served as a safe-guard against inadequate response on any of the questions and asked additional questions when it seemed necessary to clarify the information obtained by the primary interviewer. The open-ended nature of the interview and the scope of the material covered in the interview made the use of two interviewers appropriate for insuring the adequacy of the data. The primary interviewer recorded all responses on the interview guide and the secondary interviewer was responsible for tape recording the interview as another check in assuring the accuracy of information recorded on the interview guide.

\section{DATA ANALYSIS}

\section{The Parent Questionnaire}

Each parent questionnaire was coded by assigning a numerical value to each response. The data were then key punched and a frequency tally program was run on each center. The frequency tally provided information on the distribution of responses on each question. It also provided the mean and standard deviation on each question. The latter was not too useful, however, because all questionnaires were used in the tally, including those with no response on some of the questions. Since "no response" was coded 9 or 90 , depending on whether it was a one or two column code number, means and standard deviations were distorted 
and had to be recalculated.

As mentioned in the section on questionnaire design the twentyfour questions on parent attitudes toward the center programs were factor analyzed. All centers were grouped together for the factor analysis because of the small size of the parent population. Any data card showing a "no response" on any of the twenty-four questions was omitted leaving 89 respondents of the 101 returned parent questionnaires. The factor analysis made the data more manageable by consolidating the twenty-four individual questions into five factors. Factor scores were computed for each respondent on each of the five factors and center means on the factor scores were computed.

It was originally planned that the factor scores would also be analyzed in terms of the educational level of the parent, the racial membership of the parent, and whether the parent was a natural parent, foster parent, step parent, or other parent figure. This proved to be impossible, however, due to the small size of the sample which yielded very unequal distributions in stratified categories.

The other questions on the parent questionnaire were analyzed by computing the center mean by question. These means were examined in terms of relative comparability between centers. Centers that were exceptional on any variable were noted.

\section{The Staff Questionnaire}

Each staff questionnaire was coded by assigning a numerical value to each response. The data were then key punched and a frequency tally was run. As in the parent questionnaire, the frequency tally provided 
the distribution of responses on each question and the means and standard deviations for each question. Means and standard deviations on the first two parts of the questionnaire were meaningless as the response choices did not form equal intervals or have any numerical significance. Means and standard deviations on Part III of the staff questionnaire were also not used due to the maintenance of questionnaires with no response on some of the questions.

The results from the questions relating to staff ideas about the parent role in the center and the question dealing with staff reasons for involving parents were analyzed for deviations from calculated expected frequencies. Centers whose responses on a question varied considerably from the expected results were noted and trends in response across all of these questions were determined.

The nine questions dealing with staff feelings about their role in decision making were, as mentioned in a previous section, factor analyzed to make the data more manageable. All the centers were grouped together for the factor analysis due to the small size of the population. Any data card showing a "no response" on any of the nine questions was omitted leaving 45 of the 51 staff questionnaires. Factor scores were computed for each respondent on each of the five factors and center means on the factor scores were computed. 


\section{CHAPTER IV}

\section{FINDINGS}

\section{INTRODUCTION}

The intent of the present study was to provide descriptive data on five child day treatment centers. The descriptions of the day treatment centers are not exhaustive, rather they focus on data dealing with the theoretical orientation of the program, the decision making process in the center, and the parents' attitudes toward the day treatment centers. Results from each of the data collection instruments will be presented separately for greater clarity. Not all data is reported in detail in this chapter. While all results are referred to, some of the less relevant tables are contained in the appendices.

\section{THE INTERVIEW GUIDE}

The data obtained on the interview guide were open-ended data. Descriptions of the programs derived from the interview will focus on basically four areas: the theoretical orientation toward treatment, the services offered to children and their families, the requirements for parent involvement and the center's decision making process in different phases of the center's operation.

\section{Theoretical 0rientation}

All of the centers studied have milieu therapy as a primary component of child treatment. The theoretical orientation underlying the milieu, however, varies with the center. It is important to note that the orientation described for each center is a statement of emphasis 
and does not imply the exclusion of other treatment considerations. The orientation listed for each program represents a paraphrase of the director's response to the question asking for theoretical orientation toward treatment. It is sometimes difficult to discriminate between programs on this variable due to idiosyncratic labelling of program orientation. In some cases the words used to describe the theoretical orientations to treatment are different, but is is not possible to conclude a corresponding difference in orientation.

Poyama Land, Independence, Oregon, is described as an eclectic approach to treatment resting heavily on the tenets of behaviorism in the sense that the child's behavior forms the basis for treatment planning. Inferences about the child's internal mental state are made on the basis of observed behaviors.

The Child Psychiatric Day Treatment Center, Portland, Oregon, was described as a developmental, psychodynamic approach. Developmental theory is used to guide treatment planning by setting, as treatment goals, points along a developmental continuum.

The director of the Mid-Columbia Children's Center, The Dalles, 0regon, described that program as psycho-educational. In this approach, education and therapy are seen as one process. This does not seem to be too different from the orientation described by the director of the Child Center, Eugene, 0regon. That program's orientation was described as behavioral. This approach is not to be confused with behaviorism or behavior modification. It is, rather, more consonant with a learning theory model. It is based on the idea that all behavior is learned. The interventions are considered to be educational. New behaviors are 
learned and old behaviors are supplanted.

Edgefield Lodge, Troutdale, Oregon, is the only one of the five day treatment centers that has a behavioristic, data based, treatment orientation. Behavior is changed through the development and application of reinforcement techniques.

\section{Services offered to Children and Their Families}

A listing of services offered to families by the day treatment centers indicated that Edgefield Lodge differs in this respect from the other four programs. At Edgefield Lodge services are centered around child management training for parents. This includes training in reinforcement techniques through the use of one way mirrors and video tape. In the other centers services offered focus on a combination of individual, group, and marital or family counseling. At Edgefield Lodge marital therapy is available, but it is rarely used. All of the centers provide some form of follow-up services. For example, the Child Center uses telephone interviews. Poyama Land has follow-up visitation of a child in the school for a ninety day period and MidColumbia offers intensive follow-up by the family therapist for three months and a more limited follow-up by the family therapist for another six months.

\section{Requirements for Parent Involvement}

While all the centers require parent involvement, the requirements for parents; as listed by the executive directors, vary in number, flexibility, and specificity. Analysis of requirements for parents at the five centers reveals that the Child Psychiatric Day 
Treatment Center and the Mid-Columbia Children's Center have the fewest number and the least specific requirements. At Mid-Columbia parents are required to meet with the case manager and the family therapist every two weeks. They may also be required to attend a group session if there is a group that meets the needs of the parent. These groups are time limited groups formed around specific problem areas. The Child Psychiatric Day Treatment Center requires that parents express a willingness to participate in the program. The basis of participation is negotiable and varies from parent to parent.

The other three centers have more specific stated requirements. At Poyama Land parents are required to attend group meetings. There is a mothers' group, a fathers' group, and a foster parents' group. The parents must meet with the family counselor on a regular basis and with either the case manager or treatment coordinator. The frequency of these meetings is negotiable.

The Child Center requires that the parents attend intake staffing. The parents must also participate weekly in one or more family services. Which services are used is negotiated with the case manager. The parent is also required to attend staffing reviews of his child's progress every four weeks.

At Edgefield Lodge parents are required to participate in parent education groups. Parents must meet with the treatment team every nine weeks to review and plan the child's treatment program. Parents are also required to administer home programs. They must collect behavioral data on a regular basis and must demonstrate their application of reinforcement techniques. 
The Decision Making Process

Interview questions dealing with the decision making process in four phases of the center's operations elicited, in most cases, a detailed description of the procedures associated with the intake process, the hiring of new staff, evaluation of child progress in treatment, and program change. The focus in this study is not on decision making process itself but on the individuals involved in these processes. Consideration of decision making involves making a distinction between those individuals making the final decision and those who have opportunity to contribute to or influence that decision.

The Intake Process. At Poyama Land and Mid-Columbia Children's Center the final intake decision rests with the program director. At Poyama Land the intake meeting includes a child care worker, a Children's Services Division liaison worker, and a Mental Health liaison person. These individuals represent a type of screening conmittee for the intake decision. Mid-Columbia Children's Center also has a screening committee that includes the psychiatrist who spends. four hours per week working at the center, a liaison worker from Children's Services Division, and a psychologist from Mental Health. This group makes recomendations for intake which are usually, but not necessarily, followed by the director. The intake meetings at Mid-Columbia Children's Center may also include the child care worker or team leader, the family therapist, and the parents. These individuals do not have a say in the final decision, but contribute information and recommendations. The Child Care Center includes in its intake process, individuals from Children's Services Division and from Mental Health as do Poyama 
Land and Mid-Columbia Children's Center. At the Child Center, however, the participation of these representatives from other agencies is more formalized in that they are given votes. There are four votes in an intake decision, one from Children's Services Division, one from Mental Heal th and two from the Child Center.' Individuals from the center who participate in the intake meetings are the director, the counselor, and the child care worker. Also the parents are present sometimes.

Edgefield Lodge and the Child Psychiatric Day Treatment Center seem to have what could be termed a more closed intake process in terms of community involvement. Edgefield Lodge, being a larger program of which the day treatment program is only a small part, has two intake workers who interview the parents. A commitment for treatment of the child is usually made in the first interview. Supporting and supplementary information is solicited from other agencies after this interview.

At the Child Psychiatric Day Treatment Center, the intake decision is made by Senior Clinicians, who serve as supervisors for the rooms, and rotating members of the treatment team. A decision for intake requires a $100 \%$ agreement within this group. Representatives from outside groups may be present at intake to give information, but they have no vote in the intake decision.

Hiring New Staff. There was little variation among the centers in their decision making procedures for hiring new staff. All the center directors claimed staff participation at all levels. In all cases prospective child care workers spent from one to three days working alongside the staff. Staff gave feedback on their performance. At the 
Child Center, a decision to hire is based on the consensus of the staff. At Poyama Lard, the director can veto a decision made by the assistant director and the child care worker. At Mid-Columbia Children's Center, the director and the child care supervisor have the final say. At Edgefield Lodge, the program manager makes the final approval on recommendations by the team. Poyama Land was unique in their inclusion of two parent representatives in interviewing prospective family therapists.

Child Evaluation. Evaluation of a child's progress in treatment is a step in decision making about the direction of further treatment. The frequency and form of child evaluation varied considerably among the centers. These approaches included various combinations of daily logs and review of the child at regular predetermined intervals. These reviews were, without exception, carried out by the treatment teams and family therapists. Edgefield Lodge and the Child Center were unique in their involvement of the parents in a formal way in the evaluation of the child by including them in staffing and/or treatment team meetings.

Program Change. The directors were asked to describe the decision making process involved in making a program change. The program changes described by the directors were: realignment of staff at Mid-Columbia Children's Center; a new grouping of children at Edgefield Lodge; an emphasis on involvement with the schools at Poyama Land; obtaining Title I funds to increase the family therapist to full-time at the Child Center; and formation of a community team at the Child Psychiatric Day Treatment Center. With the exception of Edgefield Lodge all of the centers described a group consensus decision making process. Some 
directors described the process as one in which there was no distinction between the formal and the informal process. The directors of Poyama Land and the Child Psychiatric Day Treatment Center did point out their final responsibility for decisions made.

The Edgefield Lodge decision making process for program changes was similar but seemed to be slightly more formalized. Decision making around program changes involves the treatment director, the program manager, and the unit leaders. The rest of the staff is involved in the process, after a decision has been made, to discuss ramifications of that decision.

\section{THE STAFF QUESTIONNAIRE}

The three questions on the staff questionnaire dealing with the job titles of staff, the educational level of staff, and the field of interest of staff revealed some variation in composition of the staffs of the five day treatment centers.

Responses to the question asking for job title were classified as to whether the position reflected primary function as child care, family therapy, supervision, or education. For all centers the greatest percentage of staff was associated with child care. The Child Psychiatric Day Treatment Center revealed a somewhat lạger percentage of staff whose primary function was education. Other differences in staff distribution by center were minimal among the centers. (See Appendix).

The centers also displayed some differences in the educational level of the staff. The Child Center had a larger percentage of staff 
with masters degrees than did the other centers with $50 \%$ of the staff holding masters degrees. Mid-Columbia had a greater percentage of staff with no degree. The Child Psychiatric Day Treatment Center is the only center with an M.D. on the staff. (See Appendix).

There was also some variation among the centers in the predominant field of training of the staff members. At Poyama Land 55\% were trained in the social sciences, while at the Child Center, 50\% received training in special education. The distribution in the other three centers was more evenly represented across several fields. (See Appendix)

The first two parts of the staff questionnaire showed some differences between staff of the centers. For each of the five questions, a contingency table was constructed and expected frequencies were calculated. Differences between observed and expected frequencies in each cell of the table were calculated in order to characterize the staff responses by center to each question. Results on each question in the first two parts of the staff questionnaire will be reported separately. Question one, Part $I$, asked staff if they felt involving parents in their child's treatment was important. All staff members in all day treatment centers responded, "yes" to this question.

Question two, Part I, asked staff to select a reason for involving parents: in their child's treatment. Each choice given was intended to be representative of a treatment approach. 0ne is considered to be representative of an ego-psychology approach, one is psycho-educational, and one is behavioristic. Frequencies of response by center are reported 
in the following table.

TABLE I

CONTINGENCY TABLE: STAFF REASON FOR INVOLVING PARENTS IN CHILD TREATMENT

\begin{tabular}{lccccc}
\hline Center & $\begin{array}{l}\text { Ego } \\
\text { Psychology }\end{array}$ & $\begin{array}{l}\text { Psycho- } \\
\text { Educational }\end{array}$ & $\begin{array}{c}\text { Behavior- None of } \\
\text { istic } \\
\text { the above }\end{array}$ \\
\hline $\begin{array}{l}\text { Poyama Land } \\
\begin{array}{l}\text { Child Psychiatric } \\
\text { Day Treatment }\end{array}\end{array}$ & 0 & 5 & 0 & 4 & 9 \\
$\begin{array}{l}\text { Mid-Columbia } \\
\text { Child Center }\end{array}$ & 1 & 11 & 0 & 3 & 15 \\
Edgefield Lodge & 1 & 1 & 1 & 1 & 6 \\
\hline Total & 6 & 3 & 4 & 6 & 8 \\
\hline
\end{tabular}

At Poyama Land a larger number of staff than expected chose the "none of the above" option. Their choice of "none of the above" seems to reflect an unwillingness to select one reason for involving parents at the expense of the other reasons. The write-in responses were combinations of the ego-psychology, the psycho-educational and the behavjoristic choices with one staff member combining the ego-psychology response with the psycho-educational response, and one staff member combining the psycho-educational response with the behavioristic response. The other two staff selecting the "none of the other" response combined all three choices and qualified their statements by indicating 
that the reason for involving the parents depends on the particular parent.

A greater number of staff at the Child Psychiatric Day Treatment Center than expected chose the psycho-educational response and fewer than expected chose the behavioristic response.

Among the staff at the Child Center there was a trend for staff to select the behavioristic reason for involving parents. The same was true for Edgefield Lodge.

Staff of the Mid-Columbia Children's Center also exhibited trends away from expected frequencies. A larger than expected number of staff selected the ego-psychology response and fewer than expected chose the psycho-educational response.

The next four questions on the staff questionnaire deal with staff opinion about what the parent role in different phases of center operations should be. Results are reported separately for each question. 
TABLE II

CONTINGENCY TABLE: STAFF OPINION ABOUT

PARENT ROLE IN INTAKE.

\begin{tabular}{lccccc}
\hline Center & $\mathrm{a}^{*}$ & $\mathrm{~b}^{*}$ & $\mathrm{c}^{*}$ & $\mathrm{~d}^{*}$ & Total \\
\hline Poyama Land & 0 & 0 & 3 & 6 & 9 \\
$\begin{array}{l}\text { Child Psychiatric } \\
\text { Day Treatment }\end{array}$ & 3 & 1 & 9 & 1 & 14 \\
$\begin{array}{l}\text { Mid_Columbia } \\
\text { Child Center }\end{array}$ & 0 & 0 & 4 & 2 & 6 \\
Edgefield Lodge & 0 & 0 & 7 & 0 & 7 \\
\hline Total & 3 & 0 & 10 & 3 & 13 \\
\hline
\end{tabular}

*a - the parents should not be present at intake meetings

*b - the parents should be present at intake meetings only to give information about the child

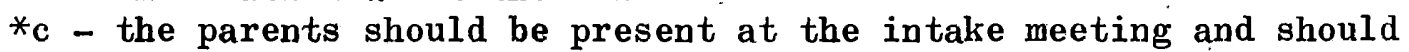
participate in decision making and planning

* d - the parents should be present at the intake meeting to be made aware of the center's expectations of them

On this question, the cells showing deviation from expected frequencies are described below. At Poyama Land, a larger number of staff than expected felt the parents should be present at intake meetings to be made aware of the center's expectations of them while fewer than expected felt the parents should participate in the decision making and planning. At the Child Psychiatric Day Treatment Center, a larger number of staff than expected felt the parents should not be present at 
intake meetings while fewer than expected thought parents should be present at intake meetings to be made aware of the center's expectations of them. Staff at Mid-Columbia did not vary significantly from the expected frequencies in any of the cells. Staff at the Child Center thought more often than expected that parents should be present at intake meetings and should participate in the decision making and planning. The same is true for Edgefield Lodge.

TABLE III

CONTINGENCY TABLE: STAFF OPINION ABOUT PARENT ROLE

IN THE HIRING OF NEW STAFF

\begin{tabular}{lcccc}
\hline Center & $\mathbf{a}^{*}$ & $\mathbf{b}^{*}$ & $\mathbf{c}^{*}$ & Total \\
\hline Poyama Land & 3 & 0 & 6 & 9 \\
$\begin{array}{l}\text { Child Psychiatric } \\
\text { Day Treatment }\end{array}$ & 9 & 5 & 0 & 14 \\
Mid-Columbia & 4 & 1 & 1 & 6 \\
Child Center & 7 & 1 & 0 & 8 \\
Edgefield Lodge & 10 & 3 & 0 & 13 \\
\hline Total & 33 & 10 & 7 & 49 \\
\hline
\end{tabular}

*a - the parents should have no say in staffing decisions

*b - the parents should meet prospective staff and have the opportunity to share impressions with the staff

*c - the parents should share in interviewing prospective staff and should have a voice in the decision to hire 
The staff at Poyama Land varied from expected frequencies in all cells with a large proportion of the staff feeling that parents should have a voice in the decision to hire new staff. Fewer than expected chose the other two options.

At the Child Psychiatric Day Treatment Center a larger number of staff than expected felt that parents should meet prospective staff and share impressions with staff members, while fewer than expected thought parents should share in interviewing and the decision to hire.

The staff of Mid-Columbia Children's Center did not vary significantly from the expected responses with most of them feeling parents should have no say in staffing decisions.

Staff at the Child Center chose the response indicating that parents should have no say in hiring of new staff more frequently than expected. Edgefield, once again, showed the same pattern as the Child Center. 
TABLE IV

CONTINGENCY TABLE: STAFF OPINION ABOUT THE ROLE OF THE PARENTS IN EVALUATION OF THE CHILD'S PROGRESS

\begin{tabular}{lccccc}
\hline Center & $\mathbf{a}^{*}$ & $\mathbf{b}^{*}$ & $\mathbf{c}^{*}$ & $\mathbf{d}^{*}$ & Total \\
\hline $\begin{array}{l}\text { Poyama Land } \\
\text { Child Poychia tric } \\
\text { Day Treatmejt }\end{array}$ & 1 & 0 & 8 & 0 & 9 \\
Mid-Columbia & 8 & 1 & 5 & 0 & 14 \\
Child Center & 3 & 0 & 2 & 1 & 6 \\
Edgefield Lodge & 1 & 0 & 5 & 0 & 7 \\
\hline Total & 2 & 0 & 9 & 3 & 13 \\
\hline
\end{tabular}

*a - the parents should not be present at evaluation meetings, but the child's progress should be discussed with them at regular intervals

*b - the parents should be present only to give information about the child's home behavior

${ }^{*} c$ - the parènts should be present at evaluation. meetings to have an opportunity to express concerns, criticisms, satisfactions, and goals for the child's treatment.

$*_{d}$ - the parents should be present at evaluation meetings and should participate in the actual preparation of the evaluation on the same basis as the staff members present.

There are variations from expected frequencies'ás described be-

low. At Poyama Land, more staff than expected felt that parents should be present at evaluation meetings to have the opportunity to express concerns, criticisms, satisfactions and goals for child treatment. Fewer than expected thought the parents should not be present at evaluation meetings.

Staff at the Child Psychiatric Day Treatment Center tended to 
think that parents should not be present at evaluation meetings. Staff at Mid-Columbia Children's Center also thought more frequently than expected that parents should not be present at evaluation meetings, while fewer than expected felt parents should be present to express concerns, satisfactions, criticisms, and goals for their child's treatment. Staff of the Child Center did not vary significantly from the expected frequencies. Edgefield Lodge staff chose responses $c$ and d more frequently than expected while selecting the choice that parents not be present at evaluation meetings much less frequently than expected

TABLE V

CONTINGENCY TABLE: PARENT ACCESS TO THEIR CHILD'S FILE

\begin{tabular}{lcccccc}
\hline Center & $\mathbf{a}^{*}$ & $\mathbf{b}^{*}$ & $\mathbf{c}^{*}$ & $\mathrm{~d}^{*}$ & $\mathbf{e}^{*}$ & Total \\
\hline Poyama Land & 1 & 1 & 3 & 2 & 2 & 9 \\
Child Psychiatric & & & & & & \\
$\quad$ Day Treatment & 0 & 9 & 3 & 2 & 1 & 15 \\
Mid-Columbia & 0 & 1 & 1 & 3 & 1 & 6 \\
Child Center & 1 & 0 & 0 & 3 & 4 & 8 \\
Edgefield Lodge & 0 & 2 & 5 & 4 & 2 & 13 \\
\hline Total & 2 & 13 & 12 & 14 & 10 & 51 \\
\hline
\end{tabular}

*a - parents should not have access to their child's file

*b - parents should have access to only certain parts of their child's file and then only when in the presence of a staff member

*c - parents should have access to only certain parts of their child's file and should be free to see those parts without a staff member present

*d - parents should have access to the entire contents of their child's file but only in the presence of a staff member

*e - parents should have access to the entire contents of their child's file at any time 
There are observable trends in staff response by center. Staff of the Child Psychiatric Day Treatment Center chose, more frequently than expected, the response which allowed parental access to only certain parts of the file and then only in the presence of a staff member. Correspondingly, they chose the other options less frequently than expected. The staff of Mid-Columbia Children's Center tended to favor access of the entire contents of the file to the parent in the presence of a staff member. The Child Center staff allowed parents greater access to the file in selecting more frequently than expected that parents could see the entire contents of the file without a staff member being present. Staff of Edgefield Lodge corresponded fairly closely with expected frequencies. Nine of the ten questions on the staff questionnaire that have not yet been discussed, were factor analyzed. These questions deal with the staff role in decision making. Three factors were generated and were subsequently named: 1) Integration into 0verall Functioning of the Center; 2) Upward Communication; and 3) Alienation from Job Requirements. Factor scores were computed for each respondent on each factor and center means on each factor were calculated. 
TABLE VI

MEAN STAFF SCORES ON FACTOR I: INTEGRATION INTO

OVERALL FUNCTIONING OF CENTER

Center

Factor Score Mean

Poyama Land

$-4.4594$

Child Psychiatric Day Treatment

$-4.8254$

Mid-Columbia

$-4.6400$

Child Center

$-4.7821$

Edgefield Lodge

$-4.1316$

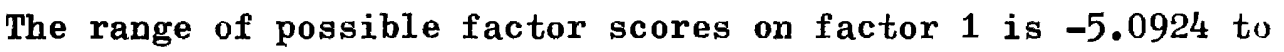

-1.2253. The more negative the score the greater the degree of staff integration into overall functioning of the center. There is virtually no distinction between center mean scores on Factor 1. All the centers show a high degree of staff integration.

TABLE VII

MEAN STAFF SCORES ON FACTOR 2: UPWARD COMMUNICATION

Center

Factor Score Mean

Poyama Land

$-4.5456$

Child Psychiatric Day Treatment

$-5.3640$

Mid Columbia

$-5.3221$

Child Center

$-5.2613$

Edgefield Lodge

$-4.9596$

The possible range of factor scores on Factor 2 is from -6.1987 to -1.0182 . The more negative the score the greater the degree of upward communication perceived by the staff of the center. All centers show a high degree of upward communication with Poyama Land and 
Edgefield Lodge showing a very slight tendency toward less upward communication.

TABLE VIII

MEAN STAFF FACTOR SCORES ON FACTOR 3:

ALIENATION FROM JOB REQUIREMENTS

Center

Factor Score Mean

Poyama Land

.4542

Child Psychiatric Day Treatment

.1427

Mid-Columbia

.5106

Child Center

.0417

Edgefield Lodge

.6668

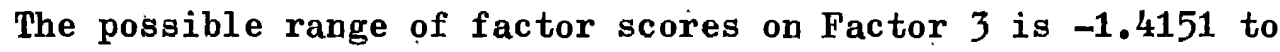
+4.2186. The more positive the score the greater the degree of alienation from job requirements. Staff of all centers seem to feel relatively un-alienated from job requirements. There is a slight trend toward greater alienation in Poyama Land, Mid-Columbia and Edgefield Lodge.

Question 10 in Part III of the staff questionnaire deals with channels and sources of information within the day treatment center. Frequency and percentage of response to the question is given in the following table. 
TABLE IX

CHANNELS OF COMMUNICATION IN THE DAY TREATMENT CENTERS

\begin{tabular}{|c|c|c|c|c|c|c|}
\hline Center & $\mathbf{a}^{*}$ & $\mathbf{b}^{*}$ & $\mathbf{c}^{*}$ & $\mathrm{~d}^{*}$ & $\mathbf{e}^{*}$ & $\mathrm{~N}$ \\
\hline \multicolumn{7}{|l|}{ Poyama Land } \\
\hline Frequency & 7 & 1 & 0 & 0 & 1 & 9 \\
\hline Percent & 77 & 11 & 0 & 0 & 11 & 100 \\
\hline \multicolumn{7}{|c|}{$\begin{array}{l}\text { Child Psychiatric } \\
\text { Day Treatment }\end{array}$} \\
\hline Frequency & 4 & 2 & 1 & 0 & 8 & 15 \\
\hline Percent & 26 & 13 & 6 & 0 & 53 & 100 \\
\hline \multicolumn{7}{|l|}{ Mid-Columbia } \\
\hline Frequency. & 0 & 1 & 2 & 0 & 3 & 6 \\
\hline Percent & 0 & 16 & 33 & 0 & 50 & 100 \\
\hline \multicolumn{7}{|l|}{ Child Center } \\
\hline Frequency & 2 & 0 & 0 & 0 & 6 & 8 \\
\hline Percent & 25 & $\mathbf{0}$ & 0 & 0 & 75 & 100 \\
\hline \multicolumn{7}{|c|}{ Edgefield Lodge } \\
\hline Frequency & 3 & 1 & 3 & 2 & 4 & 13 \\
\hline Percent & 23 & 7 & 23 & 15 & 30 & 100 \\
\hline
\end{tabular}

*a - staff meetings

*b - informal taIks with other staff at my job level or lower

$*_{c}$ :- informal talks with staff at a higher job level than my own

*d - memos and other written materials

*e - other

Staff members selecting the "other" category almost always wrote in a combination of the other four choices. The "other" categories at Edgefield Lodge more often include selections $b$ and c while the staff of the Child Psychiatric Day. Treatment Center most often said all of the above. One obvious trend is that the staff of Poyama Land much more frequently view the staff meeting as their major source of information. 
IV. THE PARENT QUESTIONNATRE

There were 135 parents in the total parent population. 102 parent questionnaires were returned. This is a percentage return of $75.6 \%$. Distribution of return by center is shown in Table $X$.

\section{TABLE X}

PERCENTAGE FETURN OF PARENT QUESTIONNAIRES BY CENTER

\begin{tabular}{|c|c|c|c|c|}
\hline Center & $\begin{array}{l}\text { Number in } \\
\text { Sample }\end{array}$ & $\begin{array}{c}\text { Number } \\
\text { Returned }\end{array}$ & & $\begin{array}{l}\text { Percent } \\
\text { Returned }\end{array}$ \\
\hline Poyama Land & $\because \quad 26$ & 24 &. & $92.3 \%$ \\
\hline $\begin{array}{c}\text { Child Psychiatric } \\
\text { Day Treatment }\end{array}$ & . 31 & 25 & & $80.6 \%$ \\
\hline Mid-Columbia & 18 & 12 & & $66.6 \%$ \\
\hline Child Center & 20 & 16 & & $80.0 \%$ \\
\hline Edgefield Lodge & 40 & 25 & & $62.5 \%$ \\
\hline
\end{tabular}

As mentioned in Chapter III, Poyama Land distributed and allowed parents to complete the questionnaires at parent group meetings. This undoubtedly accounts for the high percentage return from Poyama Land. Differences in administration may also explain the other variations in percentage returns from the centers, but there is no verifiable explanation.

Percentage returns in the sample were slightly higher for foster parents. Poyama Land and the Child Center have a larger percentage of foster parents anong their parents. This may be one factor contributing 
to their larger percentage of return. (See Appendix).

The questions on the parent questionnaire dealing with the number of contacts parents had with the centers the month prior toicompletion of the questionnaire are reported here as the mean number of contacts per center.

TABLE XI

NUMBER OF REPORTED TIMES PARENTS TALKED WITH A: STAFF MEMBER THE MONTH PRIOR TO COMPLETION OF THE QUESTIONNAIRE

Center

Center Mean

Poyama Land 8.29

Child Psychiatric Day Treatment

Mid-Columbia

Child Center

5.46

Edgefield Lodge

6.29

TABLE XII

NUMBER OF PARENT GROUP MEETINGS ATTENDED BY PARENTS THE MONTH PRIOR TO COMPLETION OF THE QUESTIONNAIRE

Center

Center Mean

Poyama Land

2.09

Child Psychiatric Day Treatment .84

Mid-Columbia

1.89

Child Center

.53

Edgefield Lodge

1.08 
TABLE XIII

NUMBER OF PARENT VISITS TO CHILD'S CLASSROOM THE MONTH PRIOR TO QUESTIONNAIRE COMPLETION

Center

Center Mean

Poyama Land

2.74

Child Psychiatric Day Treatment

2.68

Mid-Columbia

1.56

Child center

2.26

Edgefield Lodge

.72

TABLE XIV

NUMBER OF BRIEF AND CASUAL CONVERSATIONS WITH A STAFF MEMBER THE MONTH PRIOR TO QUESTIONNAIRE COMPLETION

Center

Center Mean

Poyama Land

8.52

Child Psychiatric Day Treatment

8.60

Mid-Columbịa

5.78

Child Center

4.40

Edgefield Lodge

3.08 
TABLE XV

NUMBER OF TIMIS PARENTS PICKED UP OR TOOK THEIR CHILD TO THE CENTER TIE MONTH PRIOR TO QUESTIONNAIRE COMPLETION

Center

Center Mean

Poyama Land

5.64

Child Psychiatric Day Treatment

6.92

Mid-Columbia

5.22

Child Center

6.53

Edgefield Lodge

3.84

TABLE XVI

NUMBER OF TIMES PARENTS KEPT AN APPOINTMENT WITH A STAFF MEMBER THE MONTH PRIOR TO QUESTIONNAIRE COMPLETION

Center

Center Mean

Poyama Land

4.09

Child Psychiatric Day Treatment

2.33

Mid-Columbia

1.56

Child Center

2.00

Edgefield Lodge

2.92 
TABLE XVII

NUMBER OF OTHIR REPORTED CONTACTS PARENTS HAD WITH THE CENTERS THI MONTH PRIOR TO QUESTIONNAIRE COMPLETION

Center

Center Mean

Poyama Land .34

Child Psychiatric: Day Treatment .92

Mid-Columbia .00

Child Center .13

Edgefield Lodge

2.52

The larger mean of "other" contacts at Edgefield is due to the parents reporting picking up or taking their children to the bus rather than directly to the center. The Child Psychiatric Day Treatment parents who filled in the "other" category, most frequently reported these contacts as being participation in a special therapy group.

The mean nunber of contacts for all types of contacts may reflect center requirements for parent participation or parent attitudes toward the programs. Poyama Land generally has the highest number of all types of center contacts by parents.

Results on the questions reflecting parent attitudes will be reported. The twenty-four questions were factor analyzed generating five factors which were named: 1) Mutuality of Relationship Between Parents and Staff; 2) Parent Laterality Orientations; 3) Staff Communication with Parents about their Child's Treatment Program; 4) Parent Satisfac- 
tion with Requirements for Involvement in the Center; and 5) General Satisfaction with the Day Treatment Program. Factor scores were computed for each respondent on each factor and center means were computed.

\section{TABLE XVIII}

FACTOR SCORE MEANS: FACTOR I - MUTUALITY OF RELATIONSHIP BETWEEN PARENTS AND STAFF

Center

Center Mean

Poyama Land .1656

Child Psychiatric Day Treatment $-.0379$

Mid-Columbia $-.5071$

Child Center $-.1319$

Edgefield Lodge. $-.0240$

The range of possible factor scores on Factor 1 is -3.0444 to +.7433 . The more positive the score the greater the mutuality of parent-staff relationships. All centers tend toward the higher end of the range indicating a large sense of mutuality in the relationship of parent with staff. Parents at Poyama Land tend to have the greatest sense of mutual relationship while Mid-Columbia tends to score the lowest on this factor. 
TABLE XIX

FACTOR SCORE MEANS: FACTOR 2 - PARENT LATERALITY ORIENTATION

Center

Center Mean

Poyama Land

3.6132

Child Psychiatric Day Treatment

3.1508

Mid-Columbia

$-0.5513$

Child Center

2.3696

Edgéfield Lodge

3.5192

The range of possible factor scores on Factor 2 is -8.7625 to +6.0344. The high positive scores indicate a plus laterality orientation. Parents at Mid-Columbia seem to have more minus laterality orientations than the other centers. The Child Center also tends to have a slightiy more minus laterality orientation than the other three centers. However, parents at all five centers tend to have plus laterality oxientations.

TABLE XX

FACTOR SCORE MEANS: FACTOR 3 - STAFF COMMUNICATION WITH PARENTS ABOUT THE CHILD'S TREATMENT PROGRAM

Center

Center Mean

Poyama Land

0.8651

Child Psychiatric Day Treatment

1.6657

Mid-Columbia

2.8749

Child Center

1.8046

Edgefield Lodge

1.3798

The range of possible scores on this factor is -1.5475 to +11.2312. The higher positive scores indicate a lower degree of staff communication with parents about child treatment. All center means indicate that the centers received relatively low scores on this factor indicating parents perceive satisfactory staff communication 
with them about the treatment of their children. Mid-Columbia tends to have the highest positive score, indicating lower communication, while Poyama Land has a relatively low communication score indicating higher communication.

FACTOR SCORE MEANS: FACTOR 4 - PARENT SATISFACTION WITH THE REQUIREMENTS FOR INVOLVEMENT IN THE PROGRAM

\begin{tabular}{lcc}
\hline Center & Center. Mean \\
\hline Poyama Land & -9.6835 \\
Child Psychiatric Day Treatment & -9.0916 \\
Mid-Columbia & -5.0476 \\
Child Center & -8.4097 \\
Edgefield Lodge & -9.2868 \\
\hline
\end{tabular}

The possible range of scores on Factor 4 is -12.9692 to +6.8870 . The more negative the score the greater the satisfaction with the requirements for involvement in the center. Parents in all centers seem to be satisfied with the requirements for involvement, but MidColumbia parents seem to be less satisfied with the requirements for their involvement than parents in the other centers, 
FACTOR SCORE MEANS: FACTOR 5 - PARENT GENERAL SATISFACTION WITH THE DAY TREATMENT PROGRAM

Center

Center Mean

Poyama Land

7.3378

Child Psychiatric Day Treatment

6.7067

Mid-Columbia

5.2809

Child Center

5.7650

Edgefield Lodge

6.2756

The range of possible factor scores on Factor 5 is -5.8514 to +11.1342. The higher positive scores indicate a high satisfaction with the program. Parents in all five centers seem to be relatively satisfied with the day treatment centers. Mid-Columbia tends to be less satisfied than the other programs while parents at Poyama Land tend to be most satisfied with the program. The other centers distribute evenly between the two extremes at about .5 intervals. They rank from most satisfied to least satisfied in the following order: Child Psychiatric Day Treatment, Edgefield Lodge, and the Child Center.

The three control questions on the parent questionnaire indicate minor differences in the composition of the parent groups in age, educational level, and the number of months their children have been in the program.

There was little variation in parent educational level al though parents in the Child Psychiatric Day Treatment Center tend to be slightly 
more educated and parents in Mid-Columbia tend to be slightly less educated. (See Appendix).

Parents in the Child Psychiatric Day Treatment Center tended to be slightly younger than the other parent groups while parents at the Child Center tend to be slightly older. (See Appendix).

The number of months the children of the parents in the population had been in the day treatment was higher for the Child Psychiatric Day Treatment Center and lower for Edgefield Lodge. The other three centers had nearly: identical means for the number of months the children had been in the program. (See Appendix). 
Discussion of the results of the present study will be concentrated on those findings which relate to the differences in parent reactions among centers. Though all five parent populations tended toward more favorable than unfavorable reactions, there are some general trends across centers that merit discussion. These trends and possible relationships between variables will be discussed, but no one explanation can be postulated to explain all the observed differences among centers.

The parents from Poyama Land had higher positive scores on all five factors than any other parent group in the present study. MidColumbia parents reacted the least favorably on the parent questionnaire. Discussion will focus on Poyama Land and Mị-Columbia as representatives of the most extreme scores. However, it is noteworthy that the other three centers tended to maintain the same respective positions on all five factors of the parent questionnaire.

The observed differences in parent reactions to the day treatment centers might relate to several variables included in this study. One such variable is the number of parent-staff contacts. Parents at Poyama Land recorded the highest average number of contacts on the question asking for the number of times they talked with a staff member in the preceding month. Mid-Columbia parents recorded the lowest number of contacts on the same question. This finding is suggestive of a possible relationship between number of contacts and parent reactions to the programs. 
The number of staff-parent contacts might to some degree be a function of the extent and specificity of the center's requirements for parent involvement. Poyama Land is one of the centers which required more specific types of involvement from parents as compared to centers which allowed for staff-parent negotiations of types of involvement. Perhaps parent reaction to the programs is influenced by the manner and degree in which parents are involved in the center's program.

Poyama Land is unique in its requirement that all parents must attend group meetings. Most researchers assume that parents of emotionally disturbed children commonly feel guilty about their child's problems (Noland, 1971; Des Lauriers, 1969). Guilt can be a contributing factor in lack of parent involvement. Poyama Land's use of groups may help to alleviate guilt feeling by providing the opportunity for parents to gain support by sharing their mutual concerns.

Treatment orientation, as espoused by the directors, seemed to correspond with staff choice of reasons for involving parents in the program, with the exception of Mid-Columbia. The director of Mid-Columbia articulated a "psycho-educational" approach to treatment in which education and therapy are viewed as one process. However, the majority of the staff chose as their treatment focus, "helping the parents to understand their hidden problems and unconscious processes." This is the approach reflecting an ego psychology orientation to treatment. MidColumbia was the only center in which a majority of the staff picked the ego psychology approach. Some of the differences between the expressed orientation of the director and his staff might be accounted for by the fact that the staff question referred to reasons for involving parents 
while the director was asked to define or categorize his treatment program by a descriptive label.

Poyama Land's staff selected the "none of the above" category more frequently than expected on the questions relating to reasons for involving parents. This category was chosen at a frequency significantly higher than statistically expected. The staff who chose this category indicated a preference for different combinations of the other three options. The director of Poyama Land described the program as eclectic though resting on the tenets of behaviorism. Thus, it seems that a significant number of the staff also indicated a preference for an eclectic approach. These findings support the suggestion that parent reaction is influenced by the degree to which there is staff consensus on treatment approach.

Some aspects of staff response on the questionnaire merit discussion though they did not seem to be related to parent reactions. There was little difference among the center staffs in their responses to the questions relating to their role within the organization. of interest is the fact that Edgefield Lodge's staff scored somewhat higher than the staffs of the other centers on factor 3 , the degree of alienation from job requirements. The highly favorable responses of the staff members of all five centers toward their role within the organization may be due to the relatively small size of all the centers. Mid-Columbia, the smallest center, has six staff members while the Child Psychiatric Day Treatment Center, the largest center, has fifteen staff members. Size might also be a factor in the higher degree of alienation felt by the staff of Edgefield Lodge as the day treatment program is only one 
facet of a large organization offering a variety of other programs.

Staff from Edgefield Lodge and the Child Center responded in very similar ways to the questions related to parent roles in the center. Both centers are described as behavioristic by the staff. This fact suggests that there is a relationship between theoretical orientation and staff views on the legitimate parent role within the program; (ie. parent role in intake, hiring of new staff, child evaluation, and access to files). Both groups of staff favored a more active role for parents at intake and in the child evaluation process than did the staffs of the other centers. Additionally, staff of these two behavioristic programs generally felt parents should have freer access to their child's file than was thought appropriate by staff from the other centers. In actual practice, both Edgefield Lodge and the Child Center require active participation by parents in the intake process and in periodic evaluations of their child's progress. These requirements are not common to any of the other centers.

The fact that parents are involved in evaluation in the Child Center and in Edgefield Lodge may have influenced staff response to the question relating to the parents' access to their child's file. It seems that what staff members of Edgefield Lodge and the Child Center view as the legitimate parent role correlates highly with what the center is doing in actual practice.

The findings of this thesis suggest some hypotheses for further research. They are:

(i) the greater the consensus between director and staff on theoretical orientation toward treatment of a child and his family, the more favorable parent reaction to the day treatment program. 
(2) the more specific and clearly articulated the requirements for parent involvement, the more favorable parent reaction to the day treatment program.

(3) the greater the number of parent-staff contacts, the more favorable parent reaction the day treatment program.

(4) the greater the use of parents groups, the more favorable parent reaction to the day treatment program.

The purpose of this thesis was to describe parent reactions to five child day treatment programs in the context of descriptive data on theoretical orientation toward child treatment and organizational structure of the center. It was expected that variance in theoretical orientation and organizational structure would be reflected in different parent reactions to the programs. The differences in parent reaction among centers described in this study lend some support to this expectation. However, further research is necessary to clarify the relationships between theoretical orientation, organizational structure, and parent reactions. 
Almond, Richard; Keniston, Kenneth; and Boltax, Sandra.' "Milieu "Therapeutic Process." Archives of General Psychology, 21:4 $(1969), 431-442$.

Alutto, Joseph A., and Belasco, James A. "A Typology for Participation in Organizational Decision Making." Administrative Science Quarterly, 17:1 (1972), 117-125.

Ballard, Robert G., and Mudd, Emily. "Some Sources of Differences Between Client and Agency Evaluation of Effectiveness of Counseling." Social Casework, 39:1 (1958), 30-35.

Bryce, Marvin. "The Significance of the Parental Force in Psychotherapy with Disturbed Children in an Open Residential setting." Child Welfare, 47:1 (1968), 7-16.

Caine, T: M., and Smail, D. J. "Attitudes of Psychiatrists to Staff Roles and Treatment Methods." British Journal of Medical Psychology, 40 (1967), 179-182.

- "Attitudes of Psychiatric Patients to Staff Roles and Treatment Methods in Mental Hospitals." British Journal of Medical Psychology, 41 (1968), 291-294.

DesLauriers, Austin M. Your Child is Asleep: Early Infantile Autism. Homewood, Illinois: Dorsey (1969.)

Dunkerly, David. The Study of Organizations. London and Boston: Routledge and Kegan Paul, (1972).

Green, Rose. "Treatment of Parent-Child Relationships." American Journal of Orthopsychiatry, 17 (1948), 442-446.

Hage, Jerald; Aiken, Michael; and Marrett, Cora Bagley. "Organization, Structure and Communications." American Sociological Review, $36: 5$ (1971), 860-871.

Hastorf, Albert H.; Schneider, David J.; and Polifka, Judith. Person Perception. Reading, Massachusetts: Addison-Wesley Publishing Co., (1970).

Heiting, Kenneth H. "Involving Parents in Residential Treatment of Children." Children, 18:5 (1971), 163-167.

Horenstein, David; Houston, B. Kent; and Holmes, David S. "Clients Therapists and Judges' Evaluations of Psychotherapy." Journal of Counseling Psychology, 20:2 (1973), 149-153. 
Julian, Joseph. "Organizational Involvement and Social Control." Social Forces, 47:1 (1968), 12-16.

Kronick, Doreen. "Relationship Between Professionals and Families of Children with Minimal Brain Dysfunction: A Parent's Viewpoint." Academic Therapy Quarterly, 3:2 (1967-1968), 130-134.

Larrabee, Margery M. "Involving Parents in Their Children's Day-Care Experience." Children, 16:4 (1969), 149-154.

Lewis, Jerry M. "The Organizational Structure of the Therapeutic Team." Hospital and Community Psychiatry, 20:7 (1969), 206-208.

March, James 0., Handbook of Organizations. Chicago: Rand McNally and Company, (1965).

Mayer, John, and Timms, Noel. The Client Speaks. London: Routledge and Kegan Paul (1970).

Noland, Robert L., ed: Counseling Parents of the Emotionally Disturbed Child. Springfield, Illinois: Charles C. Thomas, (1972).

Pheysey, Diana C.; Payne, Roy L.; and Pugh, Derek S. "Influence of Structure at 0rganizational and Group Levels." Administrative Science Quarterly, 16:1 (1971), 61-73.

Price, James L. Handbook of Organizational Measurement. Lexington, Massachusetts: D.C. Heath and Company, (1972).

Riese, Hertha. Heal the Hurt Child. Chicago: University of Chicago Press, (1962).

Rosengren, William R. "Organizational Age, Structure, and Orientation Toward Clients." Social Forces, 47:1 (1968), 1-11.

Rosengren, William R. Organizations and Clients-Essay in the Sociology of Service. Columbus, Ohio: Charles E. Merrill Publishing Co., Bell and Howell Co., (1970).

Schmuck, Richard A.; Runkel, Philip. J.; and Langmeyer, Daniel. Theory to Guide 0rganizational Training in Schools. Eugene, Oregon: Center for the Advanced Study of Educational Administration,(1969).

Schmuck, Hichard A., and Schmuck, Patricia A. Group Processes in the Classroom. Dubuque, Iowa: William C. Brown Co.,Publishers, (1971).

Smith, Clagett. G., and Brown, Michael E. "Communication Structure and Control Structure in Voluntary Association." Sociometry, 27 $(1964)$, 449-468. 
Vriend, John, and Dyer, Wayne. "Counseling the Reluctant Client." Journal of Counseling Psychology, 20:2 (1971), 141-147.

Wadsworth, H. G., and Wadsworth, Joanna B. "A Problem of Involvement with Parents of Mildly Retarded Children.". The Family

Coordinator. 20:2 (1971), 141-147.

Wolkon. George H.; Lanier, Daniel Jr.; and Moriwaki, Sharon. "Organizational Functioning and Care in a Children's Treatment Center." Journal of Health and Social Behavior. 12:4 (1971), 348-354. 
XIGNAddV 


\section{INSTRUCTIONS FOR CODING SYSTEM FOR PARENT QUESTIONNAIRES}

This coding system is being used to insure confidential responses on the questinnaire. Please assign a code number to each parent for whom you have some expectations for involvement in your program. It should be noted that the term "parent" includes natural, foster, step parents and both mothers and fathers. Please return a list of just the code numbers to us and retain the parent names and the corresponding code numbers in your files. Instructions for assigning code numbers are as follows,

1. Your program has been assigned the letter ( ) to designate the parent respondents from your program. Please place this letter first in each code number.

2. Assign each child who has been in your program at least one month, a 2-digit number beginning with $01,02,03$, and so on until each child has been assigned a number. Place that number immediately following your program letter.

3. The next digit is a crucial one and is somewhat difficult to explain. The end result of the coding system is that there should be a code number for each parent figure for whom you have some expectations for involvement in your program. This digit, in combination. with the following digit, serves to.identify those individuals. This digit indicates whether there are expectation for the mother and/or the father to be involved. Write a 1 following the child's identification number if the mother figure is to be involved. Write a 2 if the father figure is to be involved. If you have expectations for both the mother and the father to be involved, you will be creating two separate code numbers for each parent will be completing a questionnaire. For example, if child 01 's mother is to be involved you would write ( ) $011 \ldots$. If you also expect child 01 's father to be involved you would have a code number beginning 012... The following digit indicates whether the parent is a natural parent, a foster parent, a step parent, or some other status.

If the parent is a natural parent write $\mathrm{N}$

If the parent is a foster parent write $F$

If the parent is a step parent write $S$

If the parent is other than the above write 0

(this last group might include a grandparent who is the legal guardian for a child)

If we were to expand the sample code numbers used above, we might have ( ) $011 \mathrm{~N}$ and ( ) $012 \mathrm{~N}$ if both parents were the natural parent. 
It is possible that there could be a situation where you might expect involvement from both a natural parent and a foster parent. For example you night expect child 02 's natural and foster mothers to be involved. The code numbers would begin ( ) $011 \mathrm{~N}$ and ( ) $011 \mathrm{~F}$.

The rule is that a code number should be created for every parent figure for whom you have some expectations for involvement in the program.

4. The next digit refers to the time the child has been in the program. Remember that children who have not been in the program at least one month are not to be included in the assignment of code numbers. For this digit, write:

1 - if the child has been in the program 1, 2 or 3 months 2 - if the child has been in the program 4, 5 or 6 months 3 - if the child has been in the program 7,8 or 9 months 4 - if the child has been in the program 10,11 or 12 months 5 - if the child has been in the program over 12 months

If a child falls between categories, place him in the one which is closest. For example, if a child has been in the program 6 months and 11 days give him a.2. If a child has been in the program 6 months and 24 days give him a 3 .

5. The last digit in the code number is to indicate the parent's membership in a racial group. Write:

$$
\begin{aligned}
& F-\text { if the parent is white } \\
& G \text { - if the parent is black } \\
& \text { If - if the parent is Indian } \\
& \text { O - if the parent is other than the three above groups }
\end{aligned}
$$

6. Below are a few sample code numbers:

$$
\text { A. } 03.1 \mathrm{~N} \quad 3 \quad \mathrm{~F}
$$

This is the mother of child 03. The mother is a natural parent whose child has been in the program 7,8 or 9 months. The mother is white. The child's father might have the number A032N3F

The following number $A 042 F 1 G$ indicates a foster father of a child who has been in the program 1, 2 or 3 months. The foster father is black.

If you have any questions about the coding system, please call us collect at either of the following numbers: Virginia Spurkland 503-287-5605, Joyce Edwards 206-695-2748.

We appreciate the time you spend in coding the parents in your program. Thank you. 


\author{
PORTLAND STATE UNIVERSITY \\ P. 0. Box 751 \\ Portland, Oregon 97207 \\ School of Social Work
}

\title{
Dear Parent:
}

The day treatment center in which your child is enrolled has agreed to participate in a study of the services offered to children and their families by day treatment centers. Five day treatment centers throughout Oregon are participating in the study. Staff members and parents of all the centers are being asked to complete questionnaires. It is hoped that the information received will be useful to your center and the other centers in planning services for you and your child. If the study is to provide helpful information to the centers it is very important that each staff member and each parent returns a completed questionnaire. The study will be completed in the spring and copies of the results will be made available to each of the participating centers.

The questions in the questionnaire will be used to get an overall description of each center's program. We are not interested in how each person answers the questions, but in the ways that parents and staff as a group answer the questions. In keeping with this intent, efforts have been made to assure the confidentiality and anonymity of your answers. In other words, no one will know how you answer any of the questions. For this purpose, a coding system has been developed. The number you see on the lower right hand corner of the questionnaire is your code number which has been assigned to you by the staff of your center. Your questionnaire is to be returned directly to us and will not be seen by the staff of the center. We do not know to whom the different code numbers have been assigned. In this way, your answers will be confidential and anonymous.

We appreciate your prompt completion of the questionnaire. When it is completed, seal it in the enclosed stamped envelope and drop it in the mail. Thank you.

Sincerely. yours,

Virginia Spurkland and Joyce Edwards 


\author{
PORTLAND STATE UNIVERSITY \\ SCHOOL OF SOCIAL WORK
}

January 8, 1975

\title{
Dear Parent:
}

Not too long ago you were mailed a questionnaire by the treatment center in which your child is enrolled. A letter accompanying that questionnaire indicated that you were being asked to complete the questionnaire as a part of a study of five day treatment programs in Oregon.

Our records show that the code number of your questionnaire has not been received. We have asked your center to send you another questionnaire in the event that you have misplaced your copy. Please complete the enclosed questionnaire, put it in the enclosed, stamped envelope, and drop it in the mail as soon as possible so that your center will be more accurately represented in the study.

As mentioned in the previous letter, your answers are both confidential and anonymous. The results of the study will be made available to your center in the spring.

Thank you for your cooperation.

Sincerely yours,

Joyce M. Edwards

Virginia Spurkland 
CHILD DAY TREATMENT CENTERS.

Guide for Interview with Executive Directors

Name of Center

General description of facility (by observation)

1. Most treatment programs can be characterized in terms of theoretical orientation to treatment. How would you characterize this program?

Probe: Can you label your program in a word or two? For example, Lutheran Hamily Services could be characterized as an agency based on Transactional Analysis.

2. What services are available to the children and families you work with? 
3. What are the goals of this program for working with children and their families?

Probes: Can you be more specific?

4. Are parents required to be involved in your program?

Yes_._No

If yes, are both parents required to be involved? Yes_No

Comments

5. What are parents required to do?

Are there any exceptions to these requirements? Yes No

If yes, what are these exceptions and under what circumstances are the exceptions made? 
What is the purpose for each of the requirements of parents?

6. This is a list of the staff positions you indicated on the information. Are there any other people involved in your program such as volunteers, consultants, students, etc.?

Yes_ No_ If yes, who are they?

(Instructions to interviewer - hand director a list of all positions and say, "This list should make it easier for you to answer the following questions.")

7. Who of these people make the final decision that a child should enter the program?

(if two or more persons are indicated ask the following)

a. Is this decided in a meeting? yes no

if no: What is the procedure for making intake decisions?

if yes: Is anyone else present at the decision making meeting?

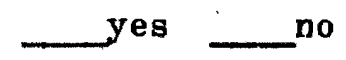


Who and for what reason?

8. Who of the people listed participate in the selection of new staff members?

Please describe the process of selecting new staff members. (What roles do the specified people play in the process) Probe: Who does what?

9. What is your procedure for evaluating a child's progress in the program?

Who on the list participates in the evaluation process? 
What do they do?

Do all the participants meet together at a. specified time and place? yes no

10. Think of a recent change that has been made in your program, for example a realignment of staff, a change in treatment emphasis, expansion of services, etc.

What was the change?

From the list of people, who was a part of the decision making group for this change?

Is this generally the decision making group program changes?

$\overbrace{\text { If no, how is it different? }}^{\text {no }}$


CHILD DAY TREATMENT CENTERS

\section{Staff Questionnaire}

I. 1. Do you feel that involving parents in their child's treatment is important? Please circle the letter of your response.
a. yes
b. no
if no, please explain your reason

a. People involved in child treatment have given different reasons for involving parents. Please circle the letter of the reason below which most closely fits your reason. (Circle only one response)

a. to help parents understand their own hidden problems and unconscious processes which may consistently frustrate and hinder attempts to assist their child.

b. to give parents both intellectual and emotional understanding of their child, his conflicts, and the accompanying defenses, and to help the parents in handling of the child in specific situations and difficulties.

c. to help parents to focus on specific problem behaviors, and to provide them with techniques to use in changing those behaviors:

d. none of the above (please explain your reason for involving parents in the space provided) 
II. The following questions are to determine what roles you think the parents should play in your center. Please circle the letter of the response which most closely describes the role you think the parent should play. Read all the responses before deciding on your answer. Circle only one response for each question.

1. What role should the parent(s) play in intake?

a. the parent(s) should not be present at intake meetings.

b. the parent(s) should be present at intake meetings only to give information about the child.

c. the parent(s) should be present at intake meetings and should participate in the decision making and planning regarding the child.

d. the parent(s) should be present at intake meetings to be made aware of the center's expectations of them.

2. What role do you think the parents should play in the hiring of new staff?

a. parents should have no say in staffing decisions.

b. parents should meet prospective staff members and should have an opportunity to share impressions with the staff.

c. parents should share in interviewing prospective staff members and should have a voice in the decision to hire.

3. What role do you think the parent(s) should play in the evaluation of their child's progress?

a. the parent(s) should not be present at evaluation meetings, but the child's progress should be discussed with them at regular intervals.

b. the parent(s) should be present at evaluation meetings only to give information about the child's home behavior.

c. the parent(s) should be present at evaluation meetings to have an opportunity to express concerns, criticisms, satisfactions, and goals for the child's treatment.

d. the parent(s) should be present at evaluation meetings and should participate in the actual preparation of the evaluation on the same basis as the staff members present. 
4. How much access do you feel a parent should have to his child's case file?

a. parents should not have access to their child's file.

b. parents should have access to only certain parts of their child's file and then only when in the presence of a staff member.

c. parents should have access to only certain parts of their child's file and should be free to see those parts without a staff member present.

d: parents should have access to the entire contents of their child's file but only in the presence of a staff member.

e. parents should have access to the entire contents of their child's file at any time.

IV. The following ten questions deal with your view of your place in the center's organization. The questions are multiple choice. Read each statement and circle the letter of the appropriate answer. Circle only one response for each question.

1. How of ten do you tell your immediate superior your own ideas about things you might do in your work?
a. never
b. rarely
c. fairly often
d. very of ten

2. Do you feel free to suggest to your superiors a different or better. way of doing something in your work?
a. never
b. rarely
c. fairly often
d. very of ten

3. Do you feel that your suggestions about different or better ways of doing things are given serious consideration?
a. none
b. hardly any
c. some
d. a lot 
4. How of ten does your job require that you do things that make little sense to you?
a. never
b. rarely
c. fairly often
d. very of ten

5. Do you have any say in decisions to adopt new treatment approaches at the center?
a. none
b. hardly any
c. some
d. a lot

6. Do you have any say in the decisions to adopt new operating procedures? (for example - new record keeping procedures, new intake procedures, etc.)
a. none
b. hardly any
c. some
d. a lot

7. How much say or influence do you have on the way the center is run?
a. none
b. hardly any
c. some
d. a lot

8. Do you feel free to try out your own ideas on your job?
a. never
b. rarely
c. fairly of ten
d. very often

9. Do you feel well informed about things that are happening which effect the center's functioning? (For example - funding changes, reorganization of staff, personnel changes, change of facility, program changes, etc.)
a. never
b. rarely
c. fairly of ten
d. very of ten 
10. How do you usually hear about what is happening at the center?

a. at staff meetings

b. in informal talks with other staff at my job level or lower

c. in informal talks with staff at a higher job level than my own

d. memos and other written materials

e. other (please specify)

V. 1. What is your job title? Please write your title in the space provided.

2. What is your educational background? Please indicate your degree and the field of your concentration. (For example -B.A. in Psychology, M.S.W., $\mathrm{PhD}$. in Clinical Psychology etc.) 


\section{CHILD DAY TREATMENT CENTERS}

\section{Parent Questionaire}

Please be sure to an swer every question.

1. How many tume have you talked with a staff member at the center this past month. either in pers on or by telephone? Please circle be low the approximate number of tumes you have talked with a

is 148 over

Approximately how many tumes have you done each of the follow: at the center this past month? Write the number of umes in the
blanks provided. For exampie:

If you visited your child's classroom three umes in the past month you would write. 3 vistied my child's classioom

If you had also attended a parent group meeting in the past month you would al so write - attended a parent group meeting

atcended a parent group meesing

visited my child's classroom

picked up or took my child to the center

talked briefty and casually with a staff member

kept an appointment with a stalf member

other (please specify)

3. The following questions are to get some idea about how parents teet about various aspects of the programs at child care centers. For each of the following statements, decide whether you strongly agree, äree, have
the statement.

If you strongty agree, circle the letters.... SA If you agree, circle the letter ......... A If you have no opinion, circle the letter..... . If you disagree, circle the letter......... D

Circle only one answer for each question
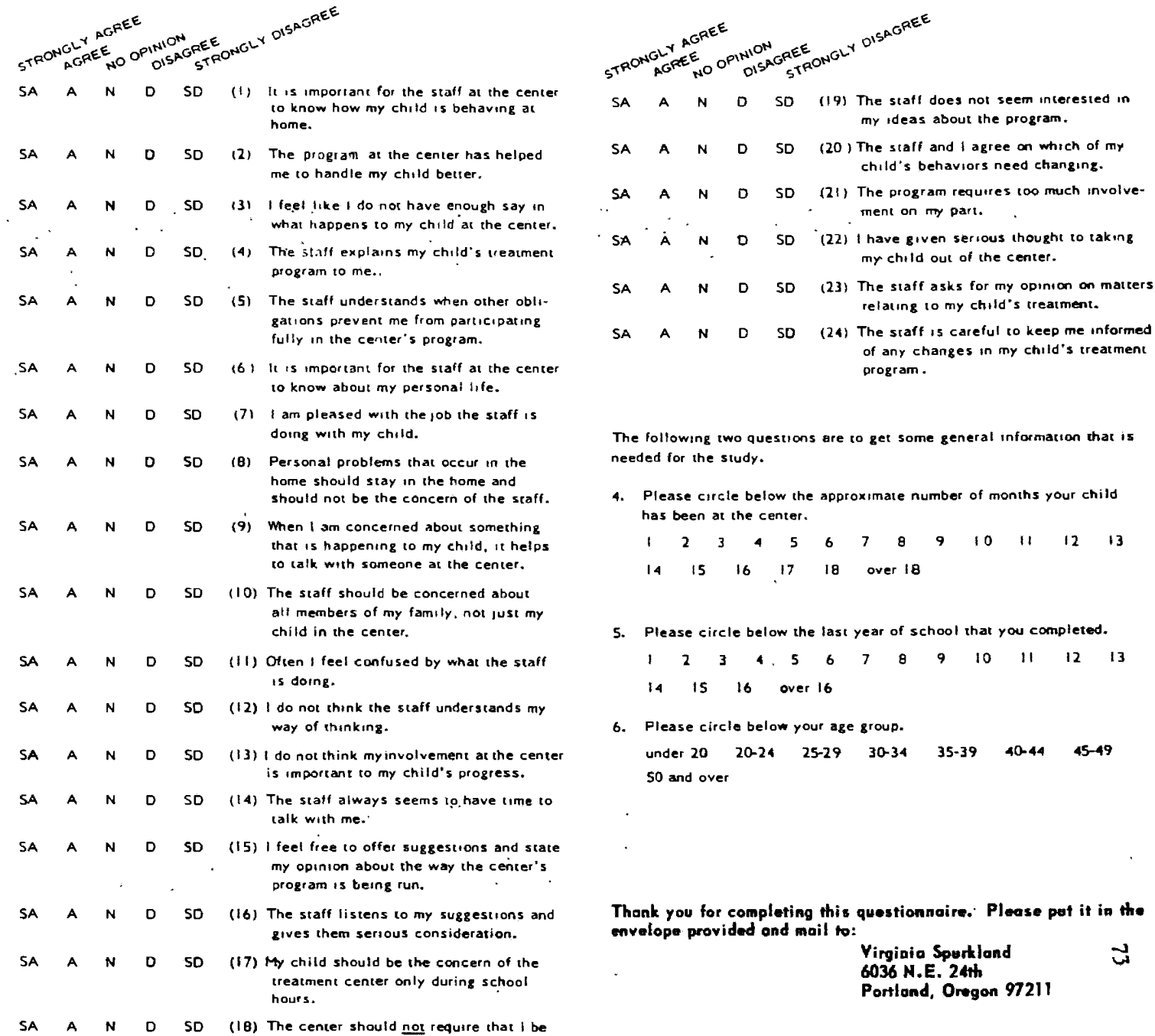

The following two questions are to get some general information that is needed for the study.

4. Please circle below the approximate number of moniths your child has been at the center.

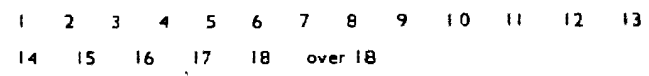

5. Please circle betow the last year of school that you completed. $\begin{array}{lllllllllllll}1 & 2 & 3 & 10 & 5 & 6 & 7 & 8 & 9 & 10 & 11 & 12 & 13\end{array}$ $14 \quad 15 \quad 16$ over 16

6. Please circle below your age group. $\begin{array}{lllllll}\text { under } 20 & 20-24 & 25-29 & 30-34 & 35-39 & 40-44 & 45-49\end{array}$ 50 and over

Thank you for completing this questionnoire. Please pet it in the envelope provided ond mail to:

Yirginia Spurklond
6036 N.E. 24th

SA A N D SD (18) The center should nor require that I be Portlond, Oregon 97211 
TABLE XXIII

FACTOR ANALYSIS ON PARENTS: ORTHOGONAL FACTOR MATRIX

\begin{tabular}{|c|c|c|c|c|c|}
\hline Variable & Factor 1 & Factor 2 & Factor 3 & Factor 4 & Factor 5 \\
\hline 1 & -0.2659 & -0.6457 & -0.0820 & 0.1675 & -0.1266 \\
\hline 2 & -0.3881 & -0.4678 & 0.0829 & 0.2919 & -0.1567 \\
\hline 3 & 0.0523 & 0.1164 & -0.1620 & -0.5438 & 0.3264 \\
\hline 4 & -0.3354 & -0.1023 & 0.7869 & 0.1609 & -0.0708 \\
\hline 5 & -0.7105 & -0.0981 & -0.0365 & 0.0556 & -0.1775 \\
\hline 6 & -0.1946 & -0.7036 & 0.1849 & -0.0564 & -0.0569 \\
\hline 7 & -0.3160 & -0.0896 & 0.1444 & 0.6328 & -0.3923 \\
\hline 8 & -0.1047 & -0.7081 & -0.1729 & -0.1681 & 0.2028 \\
\hline 9 & -0.4816 & -0.6518 & -0.0483 & 0.0213 & 0.0773 \\
\hline 1.0 & -0.2452 & -0.6370 & 0.2181 & 0.3535 & 0.1182 \\
\hline 11 & 0.1478 & 0.0398 & -0.0722 & -0.0412 & 0.8209 \\
\hline 12 & 0.4598 & 0.4803 & -0.1176 & -0.1804 & 0.4945 \\
\hline 13 & 0.0617 & 0.5173 & -0.0376 & -0.5625 & 0.1116 \\
\hline 14 & -0.6768 & -0.1434 & 0.1754 & 0.1187 & -0.1587 \\
\hline 15 & -0.7536 & -0.1769 & 0.1606 & 0.2251 & -0.1945 \\
\hline 16 & -0.7027 & -0.3949 & 0.2290 & 0.1019 & -0.0722 \\
\hline 17 & 0.1269 & 0.6750 & 0.0411 & -0.5179 & -0.0912 \\
\hline 18 & 0.2039 & 0.2757 & -0.2366 & -0.7527 & -0.0812 \\
\hline 19 & -0.6325 & 0.3499 & -0.1913 & -0.3851 & -0.0083 \\
\hline 20 & -0.5546 & -0.0571 & 0.2870 & 0.4338 & 0.0048 \\
\hline 21 & 0.5621 & 0.1726 & -0.0296 & -0.5547 & 0.0976 \\
\hline 22 & 0.3738 & 0.0745 & -0.0308 & -0.4407 & 0.5859 \\
\hline 23 & 0.0138 & -0.1089 & 0.8225 & 0.2493 & -0.0209 \\
\hline 24 & -0.4967 & -0.0880 & 0.5706 & -0.0521 & -0.2353 \\
\hline
\end{tabular}


TABLE XXIV

PARFNT QUESTIONNAIRE: DISTRIHUTION OF QUESTIONS

OVER THE FIVE FACTORS

Factor

Question

1

2

3

continued
5. The staff understands when other obligations prevent me from participating. fully in the center's program.

14. The staff always seems to have time to talk with me.

15. I feel free to offer suggestions and state my opinion about the way the center's program is being run.

16. The staff listens to my suggestions and gives them serious consideration.

20. The staff and I agree on which of my child's behaviors need changing.

21. The program requires too much involvement on my part.

1. It is important for the staff at the center to know how my child is behaving at home.

6. It is important for the staff at the center to know about my personal life.

8. Personal problems that occur in the home should stay in the home and should not be the concern of the staff.

9. When I am concerned about something that is happening to my child, it helps to talk with someone at the center.

10. The staff should be concerned about all members of my family, not just my child in the center.

17. My child should be the concern of the treatment center only during school hours.

4. The staff explains my child's treatment program to me.

23. The staff asks for my opinion on matters relating to my child's treatment.

24. The staff is careful to keep me informed of any changes in my child's treatment program. 
TABLE XXTV

PARENT QUESTIONNAIRE: DISTRIBUTION OF QUESTIONS

OVER THE FIVE FACTORS

(CONTINUED)

Factor

Question

4

5
7. I am pleased with the job the staff is doing with my child.

13. I do not think my involvement at the center is important to my child's progress.

18. The center should not require that I be involved in the program.

21. The program requires too much involvement on my part.

11. Often I feel confused by what the staff is doing.

22. I have given serious thought to taking my child out of the center.

TABLE XXV

FACTOR ANALYSIS ON STAFF: ORTHOGONAL FACTOR MATRLX

\begin{tabular}{|c|c|c|c|c|c|c|}
\hline Variable & & Factor 1 & Factor 2 & & & Factor 3 \\
\hline 1 & & -0.0397 & -0.8561 & & . & 0.1423 \\
\hline 2 & . & 0.0957 & -0.8363 & & & -0.9473 \\
\hline 3 & & -0.5541 & -0.2743 & & & -0.4046 \\
\hline 4 & & -0.0592 & -0.0825 & & & 0.9199 \\
\hline 5 & & -0.7623 & 0.1142 & . & & -0.1665 \\
\hline 6 & & -0.8257 & -0.0460 & . & & 0.0698 \\
\hline 7 & & -0.7989 & 0.1296 & . & & 0.2897 \\
\hline 8 & . & -0.4203 & -0.4530 & & $\therefore$ & -0.1354 \\
\hline 9 & & -0.7663 & -0.1781 & & & -0.0136 \\
\hline
\end{tabular}


TABLE XXVI

STAFF QUESTIONNAIRE: DISTRIBUTION OF. QUESTIONS OVER THE THREE FACTORS

3. Do you feel that your suggestions about different or better ways of doing things are given serious consideration?

5. Do you have any say in decisions to adopt new treatment approaches at the center?

6. Do you have any say in the decisions to adopt new operating procedures?

7. How much say or influence do you have on the way the center is run?

9. Do you feel well informed about things that are happening which effect the center's functioning?

1. How of ten do you tell your immediate superior your own ideas about things you might do in your work?

2. Do you feel free to suggest to your superiors a different or better way of doing something in your work?

4. How of ten does your job require that you do things that make little sense to you? 
TABLE XXVII

JOB CLASSIFICATIONS OF STAFF MEMBERS BY CENTER

\begin{tabular}{|c|c|c|c|c|c|}
\hline Center & $\begin{array}{l}\text { Child } \\
\text { Care }\end{array}$ & $\begin{array}{l}\text { Family } \\
\text { Therapy }\end{array}$ & $\begin{array}{l}\text { Super- } \\
\text { vision }\end{array}$ & Education & Total \\
\hline \multicolumn{6}{|l|}{ Poyama Land } \\
\hline Frequency & 5 & 2 & 1 & 1 & 9 \\
\hline Percent & 55 & 22 & 11 & 11. & 100 \\
\hline \multicolumn{6}{|c|}{ Child Psychiatric } \\
\hline \multicolumn{6}{|c|}{ Day Treatment } \\
\hline Frequency & 6 & 2 & 2 & 3 & 13 \\
\hline Percent & 46 & 15 & $1 \overline{5}$ & 23 & 100 \\
\hline \multicolumn{6}{|l|}{ Mid-Columbia } \\
\hline Frequency & 4 & 1 & 1 & 0 & 6 \\
\hline Percent & 66 & 16 & 16 & 0 & 100 \\
\hline \multicolumn{6}{|l|}{ Child Center } \\
\hline Frequency & 6 & 1 & 1 & 0 & 8 \\
\hline Percent & 75 & 12 & 12 & 0. & 100 \\
\hline \multicolumn{6}{|c|}{ Edgefield Lodge. } \\
\hline Frequency & 11 & 4 & 0 & 0 & 15 \\
\hline Percent & 73 & 26 & 0 & 0 & 100 \\
\hline \multicolumn{6}{|l|}{ Total } \\
\hline Frequency & 32 & 10 & 5 & 4 & 51 \\
\hline Percent & 63 & 20 & 10 & 8 & 100 \\
\hline
\end{tabular}


TABLE XXVIII

EDUCATIONAL LEVEL OF STAFF MEMBERS BY CENTER

\begin{tabular}{|c|c|c|c|c|c|c|c|}
\hline Center & $\mathbf{a}^{*}$ & $\mathbf{b}^{*}$ & $\mathbf{c}^{*}$ & $d^{*}$ & $\mathbf{e}^{*}$ & $\mathbf{f}^{*}$ & Total \\
\hline \multicolumn{8}{|l|}{ Poyama Land } \\
\hline Frequency & 0 & 0 & 6 & 2 & 1 & 0 & 9 \\
\hline Percent & 0 & 0 & 66 & 22 & 11 & 0 & 100 \\
\hline \multicolumn{8}{|c|}{ Child Psychiatric } \\
\hline \multicolumn{8}{|c|}{ Day Treatment } \\
\hline Frequency & 0 & 0 & 8 & 5 & 1. & 1 & 15 \\
\hline Percent & 0 & 0 & 53 & 33 & 6 & 6 & 100 \\
\hline Mid-Columbia & & & & & & & \\
\hline Frequency & 1 & 1 & 2 & 2 & 0 & 0 & 6 \\
\hline Percent & 16 & 16 & 33 & 33 & 0 & 0 & 100 \\
\hline \multicolumn{8}{|l|}{ Child Center } \\
\hline Frequency & 1 & 0 & 2 & 4 & 1 & 0 & 8 \\
\hline Percent & 12 & 0 & 25 & 50 & 12 & 0 & 100 \\
\hline \multicolumn{8}{|c|}{ Edgefield Lodge } \\
\hline Frequency. & 1 & 0 & 9 & 3 & 0 & 0 & 13 \\
\hline Percent & 7 & 0 & 69 & 23 & 0 & 0 & 100 \\
\hline
\end{tabular}

*a - no college degree

*b - no college degree but some training

*c - Bachelor's degree

$*_{d}$ - Master's degree

*e - PhD

$*_{f}-\mathrm{MD}$ 
TABLE XXIX

FIELD OF EDUCATIONAL CONCENTRATION OF STAFF MEMBERS BY CENTER

\begin{tabular}{|c|c|c|c|c|c|c|c|c|c|c|}
\hline Center & $a^{*}$ & $b^{*}$ & $c^{*}$ & $d^{*}$ & $e^{*}$ & $f^{*}$ & $g^{*}$ & $\mathbf{h}^{*}$ & Total & \\
\hline \multicolumn{11}{|l|}{ Poyama Land } \\
\hline Frequency & 2 & 5 & 0 & 0 & 0 & 1 & 1 & 0 & 9 & \\
\hline Percent & 22 & 55 & 0 & 0 & 0 & 11 & 11 & 0 & 100 & \\
\hline \multicolumn{11}{|c|}{ Child Psychiatric } \\
\hline Day Treatment & & & & & & & & & & \\
\hline Frequency & 4 & 3 & 1 & 0 & 1 & 2 & 2 & 2 & 15 & \\
\hline Percent & 26 & 20 & 6 & 0 & 6 & 13 & 13 & 13 & 100 & \\
\hline \multicolumn{11}{|l|}{ Mid-Columbia } \\
\hline Frequency & 0 & 0 & 0 & 1 & 0 & 1 & 0 & 2 & 4 & \\
\hline Percent & 0 & 0 & 0 & 16 & 0 & 16 & 0 & 33 & 100 & \\
\hline \multicolumn{11}{|l|}{ Child Center } \\
\hline Frequency & 1 & 0 & 0 & 4 & 0 & 0 & 0 & 2 & 7 & \\
\hline Percent & 12 & 0 & 0 & 50 & 0 & 0 & 0 & 25 & 100 & \\
\hline \multicolumn{11}{|c|}{ Edgefield Lodge } \\
\hline Frequency & 1 & 4 & 0 & 3 & 0 & 2 & 0 & 1 & 11 & \\
\hline Percent & 7 & 30 & 0 & 23 & 0 & 15 . & 0 & 7 & 100 & \\
\hline
\end{tabular}

*a - education

*b - social sciences

*c - nursing

*d - special education

*e - child development

$*_{f}$ - social work

*g - clinical psychology and psychiatry

*h - other 
TABLE XXX

PERCENTAGE RETURN OF QUESTIONNAIRES BY PARENT CATEGORY IN POPULATION

\begin{tabular}{|c|c|c|c|}
\hline $\begin{array}{l}\text { Parent } \\
\text { Category }\end{array}$ & $\begin{array}{l}\text { Number in } \\
\text { Sample }\end{array}$ & $\begin{array}{l}\text { Number } \\
\text { Returned }\end{array}$ & $\begin{array}{l}\text { Percent } \\
\text { Returned }\end{array}$ \\
\hline Natural parents & 97 & 72 & $74.2 \%$ \\
\hline Foster Parents & 26 & 21 & $80.8 \%$ \\
\hline Step Parents & 8 & 5 & $62.5 \%$ \\
\hline 0 ther & 4 & 3 & $75.0 \%$ \\
\hline
\end{tabular}

TABLE XXXI

DISTRIBUTION OF PARENT CATEGORIES IN THE DAY TREATMENT CENTERS

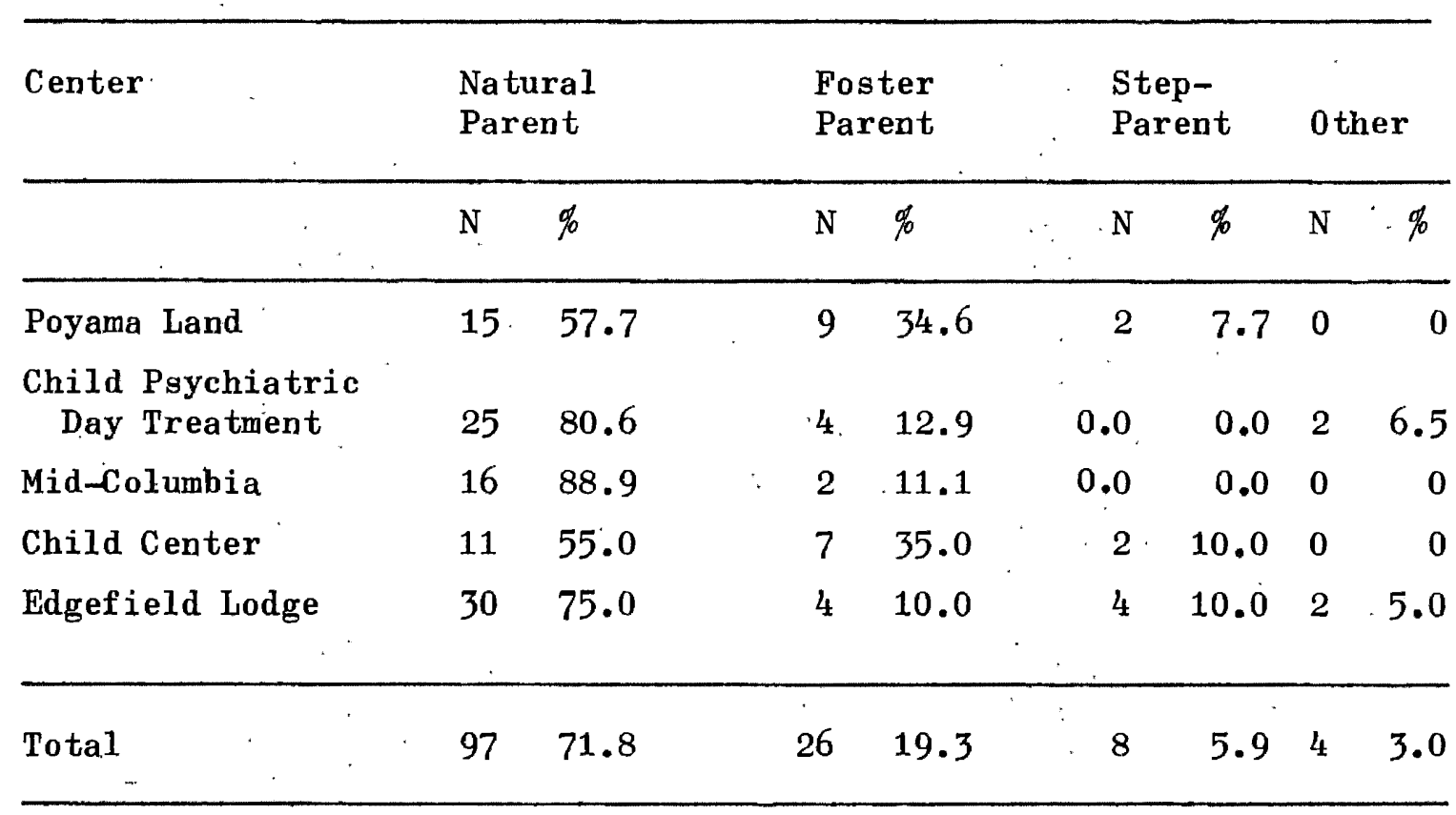


TABLE XXXII

MEAN NUMBER OF MONTHS THE CHILDREN OF THE PARENTS

IN THE POPULATION HAVE PARTICIPATED

IN THE DAY TREATMENT PROGRAMS

\begin{tabular}{lcc}
\hline Center & Center Mean \\
\hline Poyama Land & 11.57 \\
Child Psychiatric Day Treatment & 15.40 \\
Mid-Columbia Children's Center & 11.56 \\
Child Center & 11.46 \\
Edgefield Lodge & 9.48 \\
\hline
\end{tabular}

TABLE XXXIII

LAST YEAR OF SCHOOL COMPLETED BY THE PARENTS IN THE POPULATION

Center

Center Mean

Poyama Land

12.55

Child Psychiatric Day Treatment

13.28

Mid-Columbia Children's Center

11.67

Child Center

12.00

Edgefield Lodge

12.56 
TABLE XXXIV

AGE GROUP OF THE PARENTS IN THE POPULATION

Center

Poyama Land

Child Psychiatric Day Treatment

Mid-Columbia Children's Center

Child Center

Edgefield Lodge
Center Mean

$35-39$

$30-34$

35-39

$35-39$

$30-34$ 